NBSIK 8L-2604 PUBLICATIONS

\title{
Upholstered Furniture Heat Release Rates Measured With A Furniture Calorimeter
}

U.S. DEPARTMENT OF COMMERCE

National Bureau of Standards

National Engineering Laboratory

Center for Fire Research

Washington, DC 20234

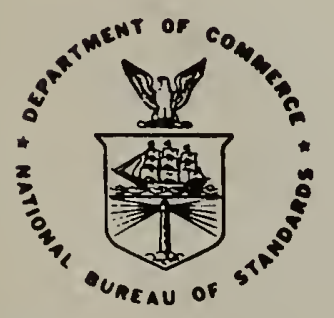



Vytenis Babrauskas, J. Randall Lawson

W. D. Walton, William H. Twilley

U.S. DEPARTMENT OF COMMERCE

National Bureau of Standards

National Engineering Laboratory

Center for Fire Research

Washington, DC 20234

December 1982

U.S. DEPARTMENT OF COMMERCE, Malcolm Baldrige, Secretary NATIONAL BUREAU OF STANDARDS, Ernest Ambler, Director 

LIST OF TABLES . . . . . . . . . . . . . . . . . . . . . . . . . . . . iv

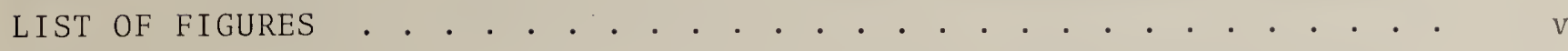

NOMENCLATURE . . . . . . . . . . . . . . . . . . . . . . . . . . . . . vi

Abstract . . . . . . . . . . . . . . . . . . . . . . . . 1

1. INTRODUCTION

2. ROOM TESTS VERSUS FURNITURE CALORIMETER TESTS . . . . . . . • . . . . 3

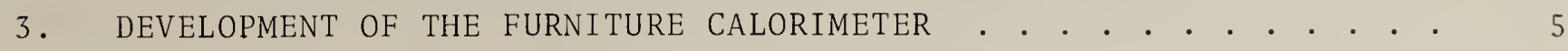

3.1 Principles of Operation . . . . . . . . . . . . . . . . 5

3.2 Practical Development . . . . . . . . . . . . . . . . 7

3.3 Calibration . . . . . . . . . . . . . . . . . . . . . 8

3.4 Maximum Apparatus Capacity . . . . . . . . . . . . . . 9

3.5 Smoke Measurement . . . . . . . . . . . . . . . . . . . . 10

3.6 Target Irradiance Measurements . . . . . . . . . . . . . . . 12

4. IGNITION SOURCE • . . . . . . . . . . . . . . . . . . . . . . . . 12

5. TEST SPECIMENS . . . . . . . . . . . . . . . . . . . . . . . . . 13

6. TEST OBSERVATIONS . . . . . . . . . . . . . . . . . . . . . . . . . 15

7. RESUlTS OF MEASUREMENTS . . . . . . . . . . . . . . . . . . . . . 16

7.1 Times to Peak . . . . . . . . . . . . . . . . . . 16

7.2 Peak Rates of Heat Release... . . . . . . . . . . . . . 17

7.3 Smoke Production. . . . . . . . . . . . . . . . . . 18

7.4 Target Irradiance . . . . . . . . . . . . . . . . . . . . . 19

7.5 Effective Heats of Combustion . . . . . . . . . . . . . . . . . . 19

7.6 Convective Heat Release Fraction . . . . . . . . . . . . . . 20

7.7 Reproducibility . . . . . . . . . . . . . . . . . 20

8. ANALYSIS FOR ESTIMATION . . . . . . . . . . . . . . . . . . . . . 21

\begin{tabular}{l} 
9. ON ACHIEVING BOTH CIGARETTE IGNITION RESISTANCE AND GOOD \\
FLAMING BEHAVIOR \\
\hline
\end{tabular}

10. SUMMARY AND CONClUSIONS . . . . . . . . . . . . . . . . . . . . . . . . . . . $\quad 24$

ACKNOWLEDGEMENTS . . . . . . . . . . . . . . . . . . . . . . . . . . 26

REFERENCES . . . . . . . . . . . . . . . . . . . . . . . . . . . . 6

APPENDIX A - ADJUSTMENTS FOR O 2 METER RESPONSE TIME • • • • • • • • $\quad$ • 59

APPENDIX B - FLOW BEHAVIOR OF THE FURNITURE CALORIMETER • . . . . . . 62

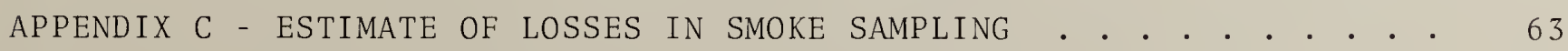


Table 1. Test specimens . . . . . . . . . . . . . . . . . . . 29

Table $2 \mathrm{~A}$. Sumary of burning rate data. . . . . . . . . . . . . . 30

Table 2 B. Supplementary data - values at peak . . . . . . . . . . 31

Table 3. Ranked peak times . . . . . . . . . . . . . . . . 32

Table 4. Ranked peak heat release values . . . . . . . . . . . . . 33

Table 5. Effect of padding type for specimens with similar fabrics . . 34

Table 6. liffect of fabric type for specimens of similar construction and padding . . . . . . . . . . . . . . . 35

Table 7. Effect of specimen mass on polyurethane foam padded specimens of similar construction . . . . . . . . . . . . . . 35

Table 8. Effect of frame type for specimens with similar padding and fabrics................ . . . . . 36

Table 9. Ranked values for smoke . . . . . . . . . . . . . . 37

Table 10. Effective heats of combustion . . . . . . . . . . . . 38

Table 1l. Estimated heat release rate data . . . . . . . . . . 39 
Figure 1. View of furniture calorimeter . . . . . . . . . . . . 40

Figure 2. Measured wastebasket heat release rates, along with adopted simplified representation . . . . . . . . . . . . . . 41

Figure 3. Wastebasket simulation burner used as the ignition source . . 42

Figure 4. Fluxes measured at the wastebasket simulation burner . . . 43

Figure 5. Chair F21 . . . . . . . . . . . . . . . . 44

Figure 6. Chair F21 near peak burning time . . . . . . . . . . 45

Figure 7. Chair F31 . . . . . . . . . . . . . . . . 46

Figure 8. Chair F31 near peak burning time . . . . . . . . . . . . 47

Figure 9. Chair F32. . . . . . . . . . . . . . . 48

Figure 10. Chair F32 near peak burning time . . . . . . . . . . 49

Figure 11. Chair F28................ . . 50

Figure 12. Chair F28 near peak burning time . . . . . . . . . . . . 51

Figure 13. Rate of heat release for specimen F21 . . . . . . . . 52

Figure 14. Effective heat of combustion measured for specimen F21 . . 53

Figure 15. Target irradiance and particulate conversion fraction for specimen F21................. . 54

Figure 16. Effect of specimen mass on rate of heat release . . . . 55

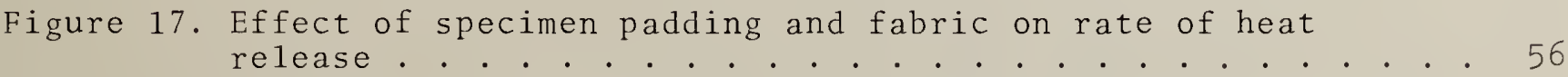

Figure 18. Relationship between mass loss rate and target irradiance flux . . . . . . . . . . . . . . . . 57

Figure 19. Relationship between actual and estimated peak values of rate of heat release ............... . 58 


$$
\begin{aligned}
& \text { A - ventilation opening area }\left(\mathrm{m}^{2}\right) \\
& \text { A - smoke chamber ceiling area }\left(\mathrm{m}^{2}\right) \\
& \text { d - duct diameter }(\mathrm{m}) \\
& \text { D - particle diffusivity }\left(\mathrm{m}^{2} / \mathrm{s}\right) \\
& d_{p} \text { - particle diameter }(\mathrm{m}) \\
& \text { F - percent transmission }\left(\frac{\circ}{0}\right) \\
& \text { h - ventilation opening height }(\mathrm{m})
\end{aligned}
$$$$
\Delta \mathrm{h}_{\mathrm{c}} \text { - lower heat of combustion }(\mathrm{kJ} / \mathrm{kg})
$$$$
k \text { - smoke extinction coefficient }\left(\mathrm{m}^{-1}\right)
$$$$
\mathrm{K} \text { - deposition velocity }(\mathrm{m} / \mathrm{s})
$$$$
\text { L - smoke measurement path length (m) }
$$$$
\mathrm{m}_{\mathrm{a}} \text { - stack air flow rate }(\mathrm{kg} / \mathrm{s})
$$$$
\dot{\mathrm{m}}_{2} \text { - stack oxygen flow rate }(\mathrm{kg} / \mathrm{s})
$$$$
\dot{m}_{\mathrm{p}} \text { - fuel mass loss rate }(\mathrm{kg} / \mathrm{s})
$$$$
m_{s} \text { - smoke mass production rate }(\mathrm{kg} / \mathrm{s})
$$$$
\mathrm{n} \text { - particle concentration }
$$$$
\mathrm{Nu}-\mathrm{Nusselt} \text { number (-) }
$$$$
\Delta \mathrm{P}_{\mathrm{f}} \text { - pressure drop across fan (Pa) }
$$$$
\dot{Q} \text { - rate of heat release (kW) }
$$$$
\mathrm{r}_{\mathrm{o}} \text { - stoichiometric oxygen/fuel ratio (-) }
$$$$
R \text { - uncorrected response }
$$$$
\mathrm{R}_{\mathrm{e}} \text { - Reynolds number (-) }
$$$$
S \text { - corrected response }
$$

Sc - Schmidt number (-)

$$
t \text { - time }(s)
$$

$t_{c}$ - time constant(s)

$t_{r}$ - rise time $(s)$

$\Delta t$ - sampling interval(s)

$\mathrm{T}$ - temperature $(\mathrm{T})$

$U$ - response function to unit step input (-) 


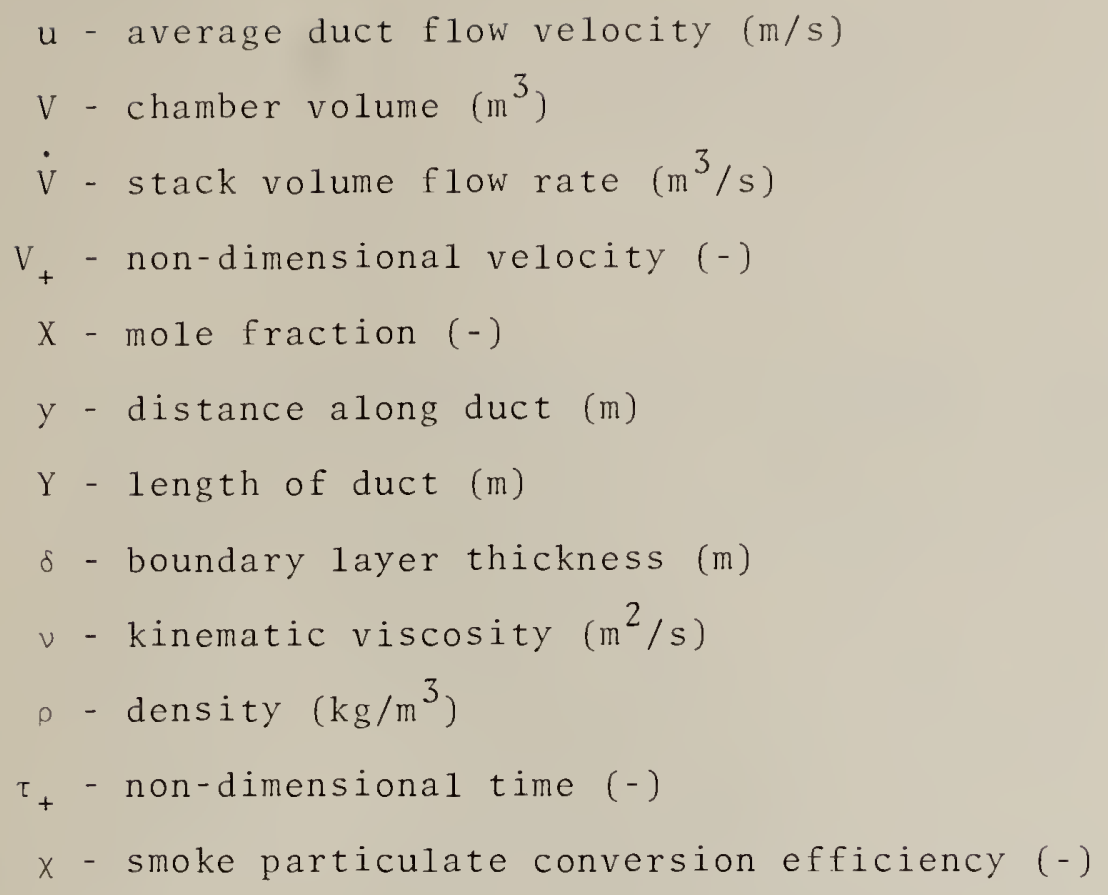



Upholstered Furniture Heat Release Rates Measured With a Furniture Calorimeter

Vytenis Babrauskas

J. Randal1 Lawson W.D. Wa1ton

William H. Twilley

\begin{abstract}
Accurate burning rate information on upholstered furniture is important for two purposes - to predict the room fire development history for a fire involving the furniture, and to relatively, but adequately, rank commercial products for a given application. Smal1scale test result data not referenced to full-scale fires lack validity, while full-scale room fires are costly and lack generality. To enable simplified but realistic full-scale testing to be done, a new apparatus, termed a furniture calorimeter was developed. Rates of heat release are measured by using the oxygen consumption principle. Tests were conducted in the furniture calorimeter on thirteen different specimens of upholstered furniture, representing typical, but carefully controlled, construction. The results showed significant heat release differences between thermoplastic and cellulosic fabrics, between frame types and between padding materials. For polyurethane foam padding, however, performance was unrelated to results of Bunsen burner type tests on the foam. The data developed (1) can be used directly in the calculation of room fire growth; (2) will form some of the reference data for development of appropriate bench-scale test procedures; and (3) can be used in some cases to estimate burning rates of similar but not identical furniture.
\end{abstract}

Keywords: Burning rate; chairs; fire tests; flammability tests; furniture; plastics; heat release rate; textiles; upholstered furniture.

\title{
1. INTRODUCTION
}

Concepts of fire protection in residential buildings have gradually been changing in recent decades. Earlier, it was tacitly assumed that in case of a fire outbreak, the room of fire origin would be lost; the concerns of fire protection were to be the protection of adjoining spaces. The focus was on fire endurance of barriers. More recently it has come about that, in some cases, protection of the initial room involved is feasible and desirable. In other cases, the consequences of the initial room fire are so severe that a more detailed quantitative understanding is needed of the initial fires in order to predict the impact on other parts of the building. 
For discrete combustible goods (as opposed to combustible room linings) detailed room fire prediction models are available [1,2]. These models require data describing the fuel objects, the most important of which is the rate of heat release. In principle, rate of heat release measurements can be made as part of room fire tests. In practice, this has been difficult to do we11, for reasons which will be discussed below. Instead, a furniture calorimeter was developed for making these measurements.

A second major application for rate of heat release data is in connection with approximate prediction models. It is now also possible to estimate the major features of a room fire, specifically the potential for flashover, by simple, algebraic engineering rules. Use of these rules also requires rate of heat release data.

Data will be presented in this report on the rate of burning of upholstered furniture. Because of the major role of upholstered furniture in many room fires, the first test series conducted in the furniture calorimeter cxamined upholstered furniture. By use of a carefully designed series of experiments where specimen construction features were separately varied, it became possible to relate quantitatively the rate of heat release to various construction aspects.

It is generally acknowledged that flammability tests can be more easily and cost-effectively done in bench-scale than in full-scale. Thus, the furniture calorimeter is not intended to be established as a standard test for rating products. Instead, the data gathered in this project will serve as a data base for developing bench-scale techniques capable of adequately predicting full-scale rate of heat release.

Finally, it is emphasized that the goal of the present series of tests was to quantify the fire performance, primarily expressed as heat release rate, of upholstered furniture subjected to flaming ignition sources. It is quite true that most furniture fires initially start from smoldering or cigarette sources and that test methods are already available [3] to measure the susceptibility to ignition. However, regulating cigarette ignitability does not address two important fire aspects: first, some fires do start from flaming sources, and these are most likely to be the ones that are fast, intense, and have the most potential for damage. Second, many fires that start as smoldering fires later erupt into open flaming. To evaluate this behavior requires burning rate tests. It also should be emphasized that, in general, there is no correlation between resistance to cigarette ignition and good behavior in terms of burning in open flaming. Indeed, the data developed 
here will suggest that for many simple, common materials there is, rather, a trade-off. Of course, choice need not be restricted to common materials.

\section{ROOM TESTS VERSUS FURNITURE CALORIMETER TESTS}

Until now most quantitative data on the performance of furniture in fires were gathered by means of full-scale room fire tests [e.g., 4,5]. Sma11-scale mockups have been used extensively [3] for cigarette ignition studies; however, for flaming behavior studies these have been 1 ittle used because of difficulties in obtaining representative behavior [6]. A room fire test is, by definition, the most realistic fire representation, yet it does not necessarily yield data of generality. Measurements of the burning rate of an item in a room can be confounded by two types of interactions-those between fuel items, if more than one is present; and those between the burning item and the surrounding room. In the general case there are interactions both between multiple fuel items and between the fuel and the room. An approach to a portion of the problem of characterizing multiple fuel item interactions has been presented [7] and will not be considered here.

A furniture item in the simplest case can be imagined burning outdoors or in a very large building, away from any other objects and with no wind. Its burning rate is then termed "free burn rate." If a room is now erected around this item, its burning rate may change for the following reasons:

- Instead of being able to entrain combustion air freely, the available air will be throttled by limited size ventilation openings. These openings may be an open doorway or window, or the room may be closed entirely. In the latter case, a fire will die out when enough of the available oxygen is consumed.

- A cloud of hot gases will collect below the ceiling and heat up the ceiling surface. Together, radiation from the heated gas and surfaces will impinge upon the fuel item and may increase its burning rate significantly. This effect may be considered negligible when the irradiance is less than 20 $\mathrm{kW} / \mathrm{m}^{2}$, measured at floor leve1. Surpassing $20 \mathrm{~kW} / \mathrm{m}^{2}$ is customarily considered to be a definition of flashover, or complete room involvement in flames. This figure is especially significant since a large number of common combustibles ignite at this irradiance. For higher irradiances, this externally forced burning can be dominant, with resulting burning rates being far above the free burn rate. 
- If the fuel item is near a wall surface, its burning will create a hot spot on the wall which will in turn reradiate to the fuel item. Such wall augmentation is especially significant in a corner configuration.

- Air inflow into a room is almost never radially symmetric. Instead, it is usually through a single opening on one side. When this is the case, it was early observed [8] that uniform fuel items, ignited all over, do not burn uniformly, but rather progressively away from the opening. Surprisingly, the number of test programs using pairs of symetrically located ventilation openings have been few $[9,10]$. Furthermore, although not yet quantified in room fires, it is known that if the inflow airstream does not impinge upon the center of the fuel, swirl is induced. Swirl is not present in an ideal freeburn fire and serves to increase the burning rate. Quintiere [11] has recently explored some quantitative effects of nonsymmetric air supply on gas flows and entrainment.

Probably the single most important engineering question that can be asked about a room fire is whether or not it will lead to flashover. (Flashover may be considered to occur when a room becomes involved in flames throughout its volume, the average hot gas temperature exceeds $600^{\circ} \mathrm{C}$ or the radiant flux to the floor exceeds $20 \mathrm{kw} / \mathrm{m}^{2}$ ). Complex fire models [2] can be used to compute this fire behavior. For design estimates, however, relatively simple guidelines can be given. A simple expression which related the rate of heat release required for flashover to occur in a room [12] is given by:

$$
\dot{\mathrm{Q}} \geq 750 \mathrm{~A} \sqrt{\mathrm{h}}
$$

where $\dot{Q}$ is the rate of heat release $(\mathrm{kW})$, A is the ventilation opening area $\left(m^{2}\right)$ and $h$ is its height $(m)$. Since door or window dimensions can, for normal rooms, be easily measured, the problem reduces to finding the maximum rate of heat release. If a single, discrete combustible item is the primary source of fuel, this value is obtainable from the furniture calorimeter. Otherwise, the state-of-the-art does not yet include a quantitative test procedure for determining $\dot{Q}$, and more empirical testing, such as conducting a room fire test, may be needed.

If properly instrumented for determining weight loss and oxygen consumption, a room fire test can be used to obtain data similar to, but not identical with, that obtainable in the furniture calorimeter. Prior to flashover, the room burning rate and the calorimeter burning rate will be similar, differing according to the considerations outlined above. If flashover is reached in the test, however, the data after that point are not 
even approximately characteristic of a free-burning fire, and thus cannot be used in the general flashover prediction above (which is not tied to a specific opening size).

In practice, good quality rate of heat release data were not obtained from room fires until recently for two reasons. Until the development of the oxygen consumption principle (discussed below), sensible heat flows had to be measured; these measurements are of high uncertainty. Also, until the development of catcher hood systems for room fire tests, the technique required doorway velocity measurements, which have been, and to some extent continue to be, difficult to make accurately [13].

\section{DEVELOPMENT OF THE FURNITURE CALORIMETER}

\subsection{Principles of Operation}

The objective of the calorimeter design is to measure the heat release and mass loss of a furniture specimen while it is burning under essentially open-air conditions. Thus, the specimen sits on a weighing platform in a large open laboratory bay while its products of combustion flow up and are collected in a hood. The oxygen levels in the hood flow are measured and that is used to determine the rate of heat release. Oxygen consumption measurements are based on the principle that while common combustibles may vary substantially in their heat of combustion (energy released per unit mass of fuel combusted), the heat released per unit mass of oxygen consumed is a near-constant. This ratio $\Delta \mathrm{h}_{\mathrm{c}} / \mathrm{r}_{\mathrm{O}}$, is taken as $13.1 \times 10^{\frac{3}{\mathrm{~kJ}} / \mathrm{kg}}$ and varies only \pm 4 percent for almost any common combustibles [14]. Here $\Delta \mathrm{h}_{\mathrm{c}}=1$ lower heat of combustion $(\mathrm{kJ} / \mathrm{kg})$ and $r_{0}=$ the mass of oxygen required to fully combust a unit mass of fuel. It can further be shown that the $\Delta \mathrm{h}_{\mathrm{c}} / \mathrm{r}_{\mathrm{o}}$ constant does not change significantly even if the combustion of the fuel is incomplete, going partially into carbon monoxide (CO) or soot. In the case of CO, an analytical correction can also be applied. It is the availability of this indirect technique that enables heat release rate measurements to be made simply, yet with good accuracy.

Figure 1 shows the practical realization of the furniture calorimeter. The primary measurements are taken in a well-mixed flow section of the instrument stack. These include flow velocity and temperature and the volume fractions of oxygen, carbon dioxide, and carbon monoxide. Oxygen was measured with a paramagnetic oxygen analyzer, while the other gases were measured with analyzers based on infra-red absorption. In this application, the equation for the rate of heat release can be written as 


$$
\dot{Q}=\frac{\Delta h_{c}}{r_{0}}\left(\dot{m}_{O_{2}}, \infty-\dot{m}_{O_{2}}\right)
$$

where ${ }^{\circ} \mathrm{O}_{2}, \infty$ is the oxygen mass flow into the combustion region and $\dot{m}_{2}$ is the oxygen mass flowing out with the exhaust. Mass flow rates of

oxygen are not directly measurable, only oxygen mole-percent being readily measurable. Parker [15] has shown that for the present conditions - metering of stack air outflow, trapping out of water vapor, and correcting for $\mathrm{CO}_{2}$ and CO in the stack gases - the rate of heat release can be witten as

$$
\begin{aligned}
& \dot{\mathrm{Q}}=\left(\frac{\Delta \mathrm{h}_{\mathrm{c}}}{\mathrm{r}_{\mathrm{o}}}\right)\left(\frac{32}{28.97}\right) \frac{\dot{\mathrm{m}}_{\mathrm{a}} \mathrm{x}_{\mathrm{O}_{2}}}{1+(\alpha-1) \phi}\left(\phi-0.34\left(\frac{1-\phi}{2}\right) \frac{\mathrm{x}_{\mathrm{CO}}}{\mathrm{x}_{\mathrm{O}_{2}}}\right) \\
& \text { with } \phi=\frac{\mathrm{x}_{\mathrm{O}_{2}}^{\circ}-\frac{\mathrm{x}_{\mathrm{O}_{2}}}{\mathrm{x}_{\mathrm{O}_{2}}^{\circ}\left(1-\mathrm{X}_{\mathrm{CO}_{2}-\mathrm{X}_{\mathrm{CO}}}\right.}}{\mathrm{X}_{\mathrm{O}_{2}}}
\end{aligned}
$$

where $X$ represents mole fractions, superscript ${ }^{\circ}$ denotes ambient conditions prior to test, $\dot{m}_{a}$ is the stack mass flow rate $(\mathrm{kg} / \mathrm{s})$, and $\alpha \simeq 1.1$. The requisite mass flow for the stack is determined with the use of a velocity probe and thermocouple. The calculations were all performed at 5 or $10 \mathrm{~s}$ intervals by use of a digital data acquisition system and computer data reduction code.

The above equations, while adequately documented [15], are not necessarily intuitively obrious. The following conceptual model may be useful in visualizing the effect of these measurements. We start by accepting the emrirical fact that each Joule of heat released corresponds to a nearly constant number of molecules of oxygen used up in the combustion process, irrespective of actual fuel composition [14]. Thus, we simply have to count up the molecules of oxygen that are used up. It is not, of course, practical to actually measure the oxygen flowing into the burning zone here. Instead, we can adopt a convenient point of view similar to that used in solid state physics to describe electron motion. There, it is useful to consider motion of "holes", which are simply the absence of an expected electron. Similarly, in oxygen consumption measurements we can imagine that the combustion process discusses a certain number of "oxygen-holes". The measurement task is to measure these oxygen-holes. 
With this point of view certain aspects of operation become very simply apparent. It is clear that we must capture all these oxygen holes in order to have a valid measurement. The exhaust flow rate, however, can be speeded up or slowed down with no error being introduced. Likewise, while no combustion product leakage should occur, an arbitrary amount of room air can be added into the exhaust, again with no error. Finally, the mixing in of a gas stream other than unvitiated room air is permissible only if it remains in constant ratio to the combustion product flow and if the combined stream is used for the initial calibration.

\subsection{Practical Development}

While the principles of determining the rate of heat release are relatively simple, the practical development of a system to do this proved to be more difficult. A hood system is required which can collect all the products of combustion without excessive dilution and without spillage. The burning specimen must not be subjected to excessive velocities or cross-drafts. The apparatus itself must not be acting as a source of radiative reflection to the specimen. Specimens both tall and squat, fast-burning and smoldering must all be accommodated and analyzed with a good signal/noise ratio. The present embodiment of these concepts is shown in figure 1 . The full exhaust gas flow capacity of the system is approximately $2.1 \mathrm{~kg} / \mathrm{s}$ under ambient conditions, decreasing to about 45 percent of that for highest temperature flows. For lower flows a provision is made to decrease the efficiency of fan suction. A water spray arrangement was installed at the intake of the fan to prevent exceeding its maximum rated temperature.

The collection hood is mounted on legs surmounting the weighing platform and is adjustable in height. Studies of buoyant plumes usually show a halfangle of $8^{\circ}$ to $10^{\circ}$ for plume spread. This was found to be quite inapplicable to furniture fires since the plume was seen to wander substantially, much more than $10^{\circ}$. To contain this flow, a set of side curtains was provided to the hood. These panels, made of sheet steel, were provided with a cooling water circuit on the outside to maintain their faces at approximately room temperature. Curtains without cooling would have been undesirable since they would act as reradiative room surfaces. With the present arrangement (the remainder of the exhaust system is substantially farther away from the burning specimen and was thus judged not to need this precaution) reradiation effects are minor, as determined by a later check against a larger test rig (see section 7.7 on reproducibility). 
In the method of operation that was used, primary reliance was placed on individual instrument calibration, with a supplementary burner calibration using a natural gas burner. By individual instrument calibration it is meant that the instruments used for measuring $\mathrm{O}_{2}, \mathrm{CO}_{2}$, $\mathrm{CO}$, velocity, and temperature were calibrated internally and were checked once in place.* The rate of heat release can then be obtained directly by the use of the equations above. Specifically, oxygen, carbon dioxide, and carbon monoxide analyzers were calibrated using known gas mixtures prior to each test. The stack flow velocities were measured with a bi-directional probe connected to a pressure transducer, which itself was calibrated using a differential pressure calibrator. The stack velocity profile was determined from measurements at 16 locations along two perpendicular traverses. The locations were chosen to correspond to equal-area annuli. The results gave a ratio of average to centerline velocities of 0.85 . This ratio did not change by more than 0.01 for varying fire size and was consequently taken as a constant. Flow values during operation were based on the single point centerline measurement, multiplied by the above shape factor.

Burner calibrations were made in the calorimeter by using a natural gas burner constructed in the form of a rectangle $0.67 \mathrm{~m}$ by $1.0 \mathrm{~m}$ with many small holes along the edges. The burner was located at $1.0 \mathrm{~m}$ above the platform to correspond to the height of the top of a burning chair. Gas flow rates were metered with an orifice meter calibrated against a dry test meter. At the time of calibration, the lower heat of combustion of the natural gas used was $50.36 \times 10^{3} \mathrm{~kJ} / \mathrm{kg}$, which compares very closely to the $50.01 \times 10^{3}$ value for methane $\left(\Delta \mathrm{h}_{\mathrm{c}} / \mathrm{r}\right.$ was taken as $\left.12.50 \times 10^{3} \mathrm{~kJ} / \mathrm{kg}\right)$. The calibrations gave the following results:

\begin{tabular}{|c|c|c|c|c|c|c|}
\hline Q supplied & $\begin{array}{c}Q \text { computed } \\
(\mathrm{kW})\end{array}$ & $\begin{array}{c}\text { Percent } \\
\text { Realized } \\
\left(\frac{0}{0}\right)\end{array}$ & $\begin{array}{c}\text { Oxygen } \\
\text { Value } \\
\left(\begin{array}{l}\% \\
0\end{array}\right.\end{array}$ & $\begin{array}{r}\mathrm{CO}_{2} \\
\left(\frac{0}{5}\right) \\
\end{array}$ & $\begin{array}{l}\mathrm{CO} \\
(\%) \\
\end{array}$ & $\begin{array}{c}\text { Air Flow } \\
\text { Rate } \\
(\mathrm{kg} / \mathrm{s}) \\
\end{array}$ \\
\hline 138 & 125 & 91 & 20.58 & 0.18 & $<0.01$ & 1.88 \\
\hline 219 & 213 & 97 & 20.20 & 0.32 & $<0.01$ & I.68 \\
\hline 279 & 259 & 93 & 19.99 & 0.43 & $<0.01$ & 1.63 \\
\hline 434 & 417 & 96 & 19.25 & 0.72 & $<0.01$ & 1.53 \\
\hline 699 & 646 & 92 & 16.45 & 2.60 & $<0.01$ & 0.97 \\
\hline 906 & 873 & 96 & 14.07 & 3.94 & $<0.01$ & 0.88 \\
\hline 1343 & 1314 & 98 & 8.87 & 6.86 & $<0.01$ & 0.80 \\
\hline
\end{tabular}

This is considered to be adequate agreement.

\footnotetext{
*The oxygen meter readings had to be corrected for response time, described in appendix
} 
The weighing platform was calibrated with fixed weights and re-zeroed prior to each test. Although the problem is not often discussed, weighing platforms used in fire tests are subject to an intrinsic error - the pull on the platform due to the buoyancy of hot gases above it. If the fire does not change size or temperature then this error is unimportant since then the measured mass loss rate is not affected. Rapid fluctuations, on the other hand, can introduce an error. It is possible to correct for this error if the buoyancy can be measured. It can be estimated from temperature data, if a large number of thermocouples are located in the fire volume [16]. Or, it can be measured with a set of pressure probes located above and below the platform. Both methods are cumbersome and detract from the simplicity of the test. Exploratory pressure measurements, however, were made during one of the tests (T38). These suggest an average error of about $1.5 \mathrm{~g} / \mathrm{s}$, but with a few sharp peaks of up to $75 \mathrm{~g} / \mathrm{s}$. The effect on the mass $10 \mathrm{~s}$ rates reported later, however, is smaller since a multi-point averaging was used to reduce noise.

After construction was completed and before specimen testing, a number of tests were conducted to characterize the flow behavior of the exhaust system. These measurements are discussed in appendix $B$.

\subsection{Maximum Apparatus Capacity}

For operational purposes, it was considered that the maximum capacity of the apparatus is $2000 \mathrm{~kW}$. The actual absolute upper limit corresponds to a zero oxygen condition in the stack and occurs at about $2500 \mathrm{~kW}$. This is accompanied by excessive stack temperatures, of approximate $1 y=00^{\circ} \mathrm{C}$ and is undesirable because the apparatus was not designed to resist these temperatures. (Fan temperatures, however, can be successfully kept below $200^{\circ} \mathrm{C}$ with the spray cooling system.) The large oxygen depletion conditions are, more significantly, undesirable because of the possibilities for poor combustion efficiency and wall quenching when a large fraction of the combustion takes place in the stack. Tests where $\dot{Q}$ values greater than $2000 \mathrm{~kW}$ were expected were conducted under a large laboratory hood. Principles of operation there were very similar to the furniture calorimeter except for higher air flow rate $(\simeq 3.0 \mathrm{~kg} / \mathrm{s})$, higher capacity $(>6000 \mathrm{~kW})$, and lower precision.

A calibration procedure was followed for the large hood very similar to the one outlined for the furniture calorimeter. The results were: 
Q supplied

(kW)

439

687

884

1297

1426

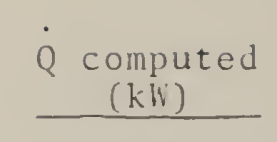

427

684

833

1160

1291
Percent

Realized

$(\%)$

97

100

94

89

91
Oxygen

Value

$(\%)$

20.09

19.58

19.33

18.59

18.28
$\mathrm{CO}_{2}$

$\left(\frac{8}{8}\right)$

0.35

0.57

0.70

1.05

1. 10
Air Flow

CO

$\left(\frac{\%}{0}\right.$

$(\mathrm{kg} / \mathrm{s})$

$<0.01$

$<0.01$

$<0.01$

$<0.01$

$<0.01$
2.96

3.06

3.20

3.12

3.07

Hood overflow can be a problem in the furniture calorimeter at higher heat release rates. No reasonable way was found to quantify the spillage since it was seen to depend on fire configuration, not just on $\dot{Q}$ alone.

Fires which were closer to the ground or closer to the hood edge were more prone to exhibit spillage. A visual estimate suggests that for well-centered fires no more than 10-15 percent would be lost at $2500 \mathrm{~kW}$, with proportionately less at lower $\dot{Q}$. No spillage was ever observed below $800 \mathrm{~kW}$. No spillage was noted under any conditions in the large hood rig.

\subsection{Smoke Measurement}

An extinction-beam photometer was installed in the exhaust duct to estimate total smoke emissions. Construction of the photometer light beam and the associated electronics was as described by Bukowski [19]. A light path distance of $0.32 \mathrm{~m}$ was used. The light source and the detector were installed behind small panes of glass inset into the side of the duct and installed with a slight air gap. The gap permits a small quantity of room air to be sucked in over these windows to help keep them free of smoke deposition. Experiments indicated that rapid soot buildup takes place if this precaution is not taken.

Smoke measurement results can be presented in a large variety of ways. It was concluded that for basic product characterization two quantities would be of interest: (1) smoke particulate production rate, $\dot{m}_{S}$; and (2) conversion efficiency of mass loss into particulate generation,

$$
x=\frac{\dot{m}_{s}}{\dot{m}_{p}}
$$

Smoke production rate can be determined as

$$
\dot{\mathrm{m}}_{\mathrm{s}}=\frac{\mathrm{kV}}{7600} \quad\left(\mathrm{~kg}-\mathrm{s}^{-1}\right)
$$

based on the assumptions and constants as developed in [20], where 


$$
\mathrm{k}=\frac{1}{\mathrm{~L}} \text { en } \frac{100}{\mathrm{~F}} \quad\left(\mathrm{~m}^{-1}\right)
$$

is the extinction coefficient, determined by using the percent transmission, $F$, and smoke path length, $L(m)$. The duct flow volume, $\dot{V}\left(m^{3}-s^{-1}\right)$, is determined at the smoke meter location by adjusting the volume flow rate in the control section according to temperature measurements at the photometer location.

Even though precautions were taken to try to keep the photometer windows clear, some soot deposition still takes place. Typically, at the end of a test, when only clear air is flowing through the duct, about 85 percent transmission may be noted. A correction scheme was developed to minimize the error from window sooting. At each scan time, $k$ was expressed as

$$
\mathrm{k}=\mathrm{k}_{\mathrm{m}}-\mathrm{k}_{\mathrm{s}}
$$

where $k_{m}$ is the measured extinction coefficient and $k_{s}$ is the window sooting term. It was postulated that at any time $t$,

$$
k_{s}(t)=k_{s}(t-\Delta t)+C_{1} k(t-\Delta t) \Delta t
$$

That is, that window sooting is augmented by a term proportional to the sootiness of the stream and to the length of time, and soot once deposited continues to stay on the window. The proportionality constant $\mathrm{C}_{1}$ is not known a priori, since adhesion characteristics of the soot particles are not known. Consequently, the suitable value of $C_{1}$ is determined iteratively for each test by requiring that the extinction coefficient for the final reading - which should be free of smoke -- be close to zero,

$$
-0.001<k<0.001
$$

Typical1y, only two iterations are required and a value of $C_{1} \simeq 5 \times 10^{-4}$ is found.

It is convenient to express results in a non-dimensional manner as $x=\dot{m}_{s} / \dot{m}_{p}$, where $\dot{m}_{p}$ is the specimen mass loss rate. Thus $x$ represents the fraction of specimen mass converted into obscuring particulates, and it must 1 ie between 0 and 1.0 . 
Results for $x$ can, in principle, be compared to bench-scale measurements [20] if losses are small or are similar in both cases. In the present study, the smoke flow, for practical reasons, was measured over 10 m downstream from the combustion zone. Thus, it can be surmised that wall losses can be substantial (appendix $C$ ). The relative performance of different specimens should, however, be correctly indicated with the measurements.

\subsection{Target Irradiance Measurements}

While the goal of the present work was not to produce a heat flux mapping from the burning items, as done in other tests [7], still some record of potential target irradiance was desired. The target irradiance is irradiance that could fall on a nearby combustible item and potentially lead to its ignition. For that purpose, a Gardon heat flux gage was placed in front of the specimen, $0.5 \mathrm{~m}$ above the platform and $0.5 \mathrm{~m}$ in front of the specimen. The gage was equipped with a purged window for recording only the radiant heat flux component.

\section{IGNITION SOURCE}

Since the present series of experiments was designed to test the flaming combustion behavior of upholstered furniture, an ignition source had to be selected which would reliably ignite the test specimens. A source corresponding to a small external fire was desired, one which would not overwhelm the specimen. In previous testing, folded newspapers or wastebaskets filled with combustibles were commonly employed. A recent investigation [7] determined the burning rate for small polyethylene wastebaskets filled with milk cartons. For the present experiments, it was decided to simulate wastebasket behavior with a natural gas burner. A good approximation to the wastebasket heat release rate is a constant $\dot{Q}=50 \mathrm{~kW}$ applied for $200 \mathrm{~s}$ (fig. 2). A burner was constructed which approximated the dimensions as the wastebasket, i.e., $250 \mathrm{~mm}$ long, $180 \mathrm{~mm}$ wide, and $250 \mathrm{~mm}$ above the weighing platform (fig. 3).

A flux mapping of this burner is shown in figure 4. The burner was placed with its $250 \mathrm{~mm}$ length flush against a noncombustible panel for making these measurements. Visible flame height corresponded to $1600 \mathrm{~mm}$ for tips of intermittent flames, with $1150 \mathrm{~mm}$ being the height of the solid flame core.

The ignition sequence consisted of positioning the ignition burner at the middle of the left side arm, almost touching. The burner was lit off and burned at a $50 \mathrm{~kW} \mathrm{level} \mathrm{for} 200 \mathrm{~s}$. After that time, burner gas flow was shut 
off and the burner itself was physically removed in order not to interfere with later collapse of the specimen.

\section{TEST SPECIMENS}

The majority of the specimens, F21 through F26 and F29 through F32, were procured from a single manufacturer. These were especially manufactured for NBS according to the following guidelines.

- Standard, typical construction details and workmanship was to be used. A contemporary but conservative style was desired.

- A minimum of different materials was to be incorporated into each piece. The pieces were to have a typical wood frame (except structural foam units), flat springs, a single type of cushioning material and a single upholstery fabric. Other combustible materials, e.g., welt cord, dust covers, etc., were to be kept to a minimum.

- The pieces were, with the exception of varying the materials, to be as similar as possible in construction. The materials chosen were systematically varied to study the dominant types available in the marketplace. Experimental, unusual, or highly expensive types were not studied. Among fabrics, cellulosic (cotton, rayon, linen) and thermoplastic types (polyolefins, nylon) are dominant. Since for flaming combustion all cellulosics tend to perform in a generically similar way, cotton fabrics were chosen from that type. Similarly, polyolefin fabrics were taken to represent thermoplastic behavior.

Specimen composition is summarized in table 1 .

Chair F21. This was chosen as the baseline case. It comprised a wood frame, "California Foam" (a commercial polyurethane foam sold as meeting California State Bulletin 117 [21] minimum requirements), polyolefin fabric, and was of typical easy chair size. The California test for foams is a vertical Bunsen burner test with criteria based on burn length, afterflame time, and afterglow time.

Chair F22. This was a chair using fire retardant (FR) cotton batting and Haitian cotton fabric, otherwise similar to F21. The seat cushion batting was solid -- the cushion did not have springs nor was it tufted.

Chair F23. This was a chair identical to chair F22, except for having a polyolefin upholstery fabric. 
Chair F24. This was a chair identical to chair F2l except for having a Haitian cotton upholstery fabric.

Chair F25. This was a chair identical to chair F2l except that it had standard, non-California polyurethane foam.

Chair F26. This chair used all the same materials as chair F2l except that it was designed with thinner construction and of lower weight.

Chair F27. This chair was tested at the request of the Consumer product Safety Commission (CPSC) and was identical to a specimen tested for smoldering behavior in their laboratories (manufacturer $\mathrm{H}$ ). The chair was of complex construction. The seat cushion consisted of polyurethane foam, covered with a layer of polyester batting, covered by a cotton inner fabric, then upholstered with a quilted fabric which contained a polyolefin batting layer sandwiched between two cotton layers. The sides and back had the quilted upholstery fabric on top of coarse olefin mesh on the outside. Inside of the arms and back were layers of cotton/polyester batting and polyolefin mesh. The seat and back areas also had layers of pressed vinal fiber pads. (Vinal fibers are made of vinyl alcohol polymer.) The structure was a conventional wood frame and steel springs.

Chair F28. This chair was also tested at the request of CPSC and was identical to a specimen tested in their laboratories (manufacturer B). The seat cushion consisted of polyurethane foam, covered with a thin layer of polyester batting, covered by a cotton corduroy upholstery fabric. The back was covered with the corduroy fabric on top of a polyolefin mesh, while the sides also included a layer of cotton/polyester batting. Inside of the arms was padded with cotton/polyester batting and a thin layer of polyurethane foam. The back cushion was stuffed with polyester batting, held in with a non-woven polyolefin fabric. The seat deck and inside back area were padded with cotton batting; in addition, the seat deck contained a thin spring insulator pad of bonded miscellaneous fibers. The structure was a conventional wood frame and steel springs.

Chair F29. This chair, similar to chair F25, used non-California foam and polyolefin fabric. It was obtained in order to study the effects of a polypropylene structural foam frame. The shape of the chair was somewhat more curvy and old-fashioned. (Structural foam frames are made by only a few manufacturers and are typically not available in simple, contemporary styles. This, we have been told, is because at present the simpler designs would not be cost-competitive compared to analogous wood frames.) 
Chair F30. This chair was similar to chair F29, except that the frame was made from polyurethane structural foam. Non-California foam and polyolefin fabric were used.

Chair F31. This was a loveseat (two-seater), identical in materials to chair F21, except for greater length and weight.

Chair F32. This was a sofa, identical in materials to F21 and F31.

Chair F33. This was a loveseat, similar in size to chair F31, except of mixed foam and cotton batting stuffing, with cotton upholstery fabric. A detailed analysis is not available.

Photographs of typical furniture items are shown in figures 5, 7, 9 and 11 .

\section{TEST OBSERVATIONS}

The ignition source burner successfully ignited all test specimens. Ignition times were short - - on the order of $15 \mathrm{~s}$ for thermoplastic fabrics - and somewhat longer for cellulosic ones. Exact times were not recorded because of the difficulty of observing ignition obscured by the birner flame. As a measure of the time scale, the time to peak is considered much more important, as discussed below. The left (occupant's view) side arm, being adjacent to the burner, was the first to burn. From there flaming usually progressed to the outside back of the chair. A little later flames would start across the seat cushion and the inside back. The upholstery, on the right side arm melted in about $80-120 \mathrm{~s}$ for the case of thermoplastic fabrics. This allowed rapid fire involvement of the foam underneath. In the case of cellulosic fabrics, the spread was much slower. The right side arm typically ignited not from radiation at a distance, but simply at the time when contiguous flame spread reached it, at about $250 \mathrm{~s}$. The front of the chair was the last to get involved in all cases.

Most specimens showed some pool burning underneath the chair since even the cotton batting units had a polyolefin dust cover underneath the seat deck. Some California foam specimens showed spurting of burning liquified polyurethane foam in small streams at the side. Neither this phenomenon nor the pool burning was judged to provide any significant increase in other item ignition potential, beyond that due to high radiant heat fluxes. 
The active burning period normally did not last beyond about $180 \mathrm{~s}$, since in that time the majority of foam and fabric would be consumed. Total burning time is very difficult to define since the last bit of smoldering may not be extinguished for several hours. Generally by about $1800 \mathrm{~s}$ the heat release rate was down to 50 to $100 \mathrm{~kW}$, while at $3600 \mathrm{~s}$ it was around $25 \mathrm{kw}$. For wood frames, total collapse had occurred by about $1500 \mathrm{~s}$. For the polyurethane frame specimen, F30, collapse had occurred by $1200 \mathrm{~s}$, while for the polypropylene frame specimen, F29, collapse was at around $900 \mathrm{~s}$. This difference could be anticipated since the F29 frame melted during the burning and, in fact, contributed to the fire at the peak burning time, while the F30 frame was not thermoplastic and tended instead to char.

\section{RESULTS OF MEASUREMENTS}

A summary of the data is presented in table 2. Detailed performance is illustrated for specimen F2l in figures 13 through 15. For purposes of this preliminary analysis, it was considered that there are two primary variables of interest - - the peak rate of heat release and the time to reach the peak. The reasons for concern with the peak intensity are self-evident. The time to reach the peak is considered important because in many fires detection may be feasible at or very shortly after ignition. Thus, occupant escape time can be controlled by the fire growth rate. In a scenario involving a specific burn room, the appropriate method of analysis [16] would be to compute the times in each case that are available before some defined limit of untenability is reached. This is possible to do with the present data by using them as input to a computer room fire model. Here, however, we will merely rank the specimen behaviors in terms of the time from start of test to peak burning rate.

\subsection{Times to Peak}

Table 3 shows the ranked peak times. Three distinct groups of results appear. Specimen F22, while showing flaming combustion from about $100 \mathrm{~s}$ to $1200 \mathrm{~s}$, did not show a substantial rate of heat release peak (fig.. 16). The highest numerical value was registered at $910 \mathrm{~s}$. Specimens F24, F27, F33, F33, F23, and F28 showed peak times in the range of 420-650 s. Finally, specimens F21, F25, F32, F26, F30, F31, and F29 burned rapid1y and showed peaks in the range of 220-280 s. The relative ranking within each of these groups is not considered significant. The differences in construction of the specimens in each of these groups are striking, however. Clearly the slowest fire development occurred with an all-cellulosic construction. The fastest fire buildup happened when polyurethane foam padding is combined with thermoplastic fabric upholstery. Constructions using cellulosic fabrics with 
polyurethane foam padding or, conversely thermoplastic fabrics with cotton batting showed a similar, intermediate buildup time. Mixed type fillings also fall into this category. It can be noted that foam type, i.e., whether ordinary or "California" type, showed no effect on rankings in these experiments.

\subsection{Peak Rates of Heat Release}

Peak rates of heat release are ranked in table 4. Again, three distinct levels of performance can be seen. The al1-cellulosic specimen, F22, performed the best, releasing only $370 \mathrm{~kW}$ at peak. Next came a large number of specimens clustered in an intermediate heat release range, 700 to $1060 \mathrm{~kW}$. Finally came a group showing rates 2 to 4 times as large as the previous, with values ranging from $1950 \mathrm{~kW}$ to $3120 \mathrm{~kW}$. With two exceptions, the members of the best, intermediate, and lowest groups were the same for both the time to reach the peak and for the peak burning rate itself. The differing ones were F26 and F30. Both of these have thermoplastic upholstery and polyurethane foam padding. Chair F26 was a "minimum weight" specimen, so while it reached its peak burning rate quickly it did not have as much fuel to burn as other specimens. Chair F30 had the rigid polyurethane foam frame. The results indicate that while replacing cotton batting padding with flexible polyurethane foam normally acts to increase the burning rate significantly, replacing the wood frame with a comparable one of rigid polyurethane foam not only did not increase the heat release rate but significantly decreased it. This is perhaps not unexpected in view of the significantly different fire behavior of rigid and flexible polyurethanes.

A detailed comparison of the effects of construction features is presented in figures 16 and 17 and in tables 5 through 8. Table 5 shows the effect of different padding types, for a given fabric. Type of foam ("California," or ordinary) is seen to have no effect. For a given fabric type, however, cotton batting construction produced less than half the rate of heat release as polyurethane foam or mixed types. Mixed type constructions can be of various sorts but - - within a fairly wide amount of scatter -- compare in heat release rate to the al1-foam and not to the all-cotton batting types.

The effect of fabric type is explored in table 6. For a given filling material type, the cellulosic (cotton) fabric specimens had a rate of heat release of less than half of the thermoplastic (polyolefin) fabric specimens. 
Within a given construction type, total specimen mass can be expected to be a major factor. The relationship is shown for polyurethane foam types in table 7. An approximately 1 inear dependence on specimen mass is scen. A relationship of this type is expected of all constructions where the chair burns in a reasonably fast way, with visible flaming, and burns up almost completely. Highly retarded types of foams are available which burn slowly, primarily by smoldering, and are not consumed in less than several hours, if at al1. It is expected that a linear relationship would not hold for such chairs and that increasing their mass would increase the total heat cvolution but little. No units of this kind were tested since they are not readily available on the commercial market. A similarly slow burning behavior can also be expected in the larger sizes of a cotton batting/cellulosic fabric type; however, no specimens of this description were tested other than F22.

Finally, frame type is seen to have a significant effect on the peak rate of heat release, though not on the time to reach the pcak (table 8). Traditional wood framing is shown to exhibit an intermediate behavior.

Structural plastic foam chair frames are available in two types - thermoplastic (polypropylene and polystyrene) and thermosetting (rigid polyurethane). Polystyrene frames were not tested because they are used only in specialized applications and are not readily available. The chair with the polypropylene frame, F29, showed a peak rate of heat release almost identical to that of the comparable wood frame unit, F21. It, however, had only half the mass of F21. Thus, on a mass basis it would have to be considered twice as fast burning. (Component weight breakdowns are not available, but table 8 suggests that it is not unreasonable to roughly estimate peak rates of heat release on the basis of total mass.) The polyurethane frame specimen, F30, showed considerably slower burning for a roughly similar specimen mass. A detailed explanation is not available other than the suggestion that this frame is not only slow to contribute to fire itself, but also that by maintaining its integrity it can help reduce fuel contribution from the uncovering of fresh fue 1 .

\subsection{Smoke Production}

Smoke production values occurring near the peak burning time are reported in table 2. It must be observed that while the numbers are expressed as nondimensional particulate conversion efficiencies, the values are not apparatusindependent. At least one requirement for apparatus independence is that all of the smoke flow past the measuring section. This is difficult to do since it would require that the measurements be taken more or less at the flame tip. In our apparatus this area is hot and not readily accessible. The 
measurement station is located at a more accessible location further downstream, but over this distance smoke losses occur and soot is deposited on duct walls (if this were not the case, the photometer windows would never need cleaning). Loss estimates are considered in appendix $C$.

Smoke measurements are shown ranked in table 9. The six poorest performing specimens all had polyurethane foam padding and thermoplastic fabric upholstery. The poorest performing specimen, F29, was distinguished by having a polypropylene foam frame, whose rapid burning properties have been discussed above. Reliable data could not be obtained on the a11-cotton specimen, F22, nor on F33. From the available data, however, it is evident that the polyurethane foam/thermoplastic fabric combination is more prone to smoke production than any other combination, and that this tendency can be exacerbated by the use of a thermoplastic foam frame.

\subsection{Target Irradiance}

Peak target irradiance values are also given in table 2. In [7] a simplification was established by dividing target fuels into three groups. The "especially easily ignitable" ones could ignite at an irradiance of $10 \mathrm{~kW} / \mathrm{m}^{2}$. Normal ignitability level was taken as $20 \mathrm{~kW} / \mathrm{m}^{2}$, while "difficult to ignite" objects corresponded to $40 \mathrm{~kW} / \mathrm{m}^{2}$. The furnishings examined in [7] were primarily slow-burning institutional and office furniture, as contrasted to the residential type items used in the present series. A comparison between the maximum radiant flux values observed during the course of the present tests and those recorded in the previous test series is shown in figure 18. The fluxes, for a given mass loss rate, were substantially lower in the present series. This is partly explained by the fact that the relationship derived from the earlier tests was taken on a worst case basis. In those tests there was a substantial difference between worst case and average or typical performance. In the present case there is little deviation from a single relationship, as shown by the close fit of points on figure 18 .

\subsection{Effective Heats of Combustion}

For modeling room fires, for estimating fuel loads and for other purposes, it is often desirable to know approximate heats of combustion for furniture. Effective heats of combustion were calculated as $\dot{Q} / \dot{m}_{p}$, averaged for several data scan intervals to minimize noise contributions. A typical computed heat of combustion curve is shown in figure 14 for specimen F21. In table 10, a summary is given, grouped according to type of construction. Differences in padding and fabric do make some difference, but still for wood-framed specimens 
most effective heat of combustion values are concentrated in the narrow range of 14.6 to $17.9 \mathrm{MJ} / \mathrm{kg}$. Polypropylene framed construction, however, results in significantly higher values, due to the high value of the net heat of combustion for polypropylene- $-43.2 \mathrm{MJ} / \mathrm{kg} \mathrm{[22].} \mathrm{The} \mathrm{average} \mathrm{effective} \mathrm{value}$ for specimen $\mathrm{F} 29$ was $35.1 \mathrm{MJ} / \mathrm{kg}$, approximately double of that for the others. Most specimens showed a behavior similar to F2l--higher initial values of the heat of combustion were followed by lower values for charring frame combustion.

\subsection{Convective Heat Release Fraction}

Attempts are sometimes made to characterize materials by the fraction of their heat release that goes into convective and into radiative heat. This partition is possible to uniquely describe only in a completely free, undisturbed ambient environment. Thus, while this convective quantity may be defined simply as the sensible enthalpy leaving an imaginary hemisphere surrounding the specimen, its actual measurement would be difficult. In a more usual situation, as in the present case, convective heat output can be defined as the enthalpy flow measured in a collector hood. This measurement does not represent the theoretical convective fraction because losses occur in the duct ahead of the measuring section and because the measured temperature is not the true gas temperature. In the furniture calorimeter the convective fraction, measured at the velocity station, ranged from 31 percent to 58 percent. (In the large hood experiments the values were from 12 percent to 21 percent.)

Alternatively, in truly open burning the total radiative output may be measured with a radiometer located far away from the burning object and viewing all its flame volume [23]. This, again, cannot be readily implemented in the furniture calorimeter.

\section{7 Reproducibility}

In full-scale fire testing replicability is often an area of significant concern. It is a general observation that to date more success is customarily had in producing well-replicatable measurements in bench-scale tests than in full-scale tests. In addition to the higher intrinsic variability in fullscale results, costs have to be considered. While it is usually feasible to conduct three to 12 replicate measurements with bench-scale tests, such an endeavor is normally not affordable in full-scale testing. Instead, it has to be sufficient to retest only one or two specimens. In the present tests, it was decided to test reproducibility by using two different scale but same principle apparatuses. Chairs F31 and F21 were tested twice, once in the 
furniture calorimeter and once under the large hood. For F31, a complete test record for the furniture calorimeter test is not available since its capacity was exceeded at $2500 \mathrm{~kW}$. Up to that point, however, the rate of heat release curves are similar, with a time shift of about 20 s (test T37 faster than T31).

A complete comparison is available for chair F21, with test T19 being conducted in the furniture calorimeter and test T45 under the large hood (fig. 13). Agreement of both rate of heat release and time to peak is to within 7 percent. This comparison also empirically demonstrates that up to at least the $2000 \mathrm{~kW}$ level there are no systematic discrepancies in the furniture calorimeter due to limited entrainment, incomplete combustion, or limited wall cooling (or, at least, that such errors cancel out).

\section{ANALYSIS FOR ESTIMATION}

The ultimate goal of the project of which this work was a part was to produce an engineering methodology for testing upholstered furniture items to determine their expected burning rates. To do this requires that quantitative tests be made available and run on whole or partial specimens of the kind considered. The bench-scale test development activities are intended to lead to this goal.

There are certain applications, on the other hand, where it is desired not to test and rate a specific article from a given manufacturer, but rather to describe, in an approximate way, the typical burning behavior of a class of articles. For this purpose we can, and indeed should, use only very limited, easily obtainable information. During the current ful1-scale test series a significant amount of information was collected on a wide variety of upholstered furniture pieces.

A simple model is, therefore, proposed that may be used for estimating the peak rate of heat release of some common classes of upholstered furniture items. Material types not explicitly listed (such as metal frames) have not yet been characterized. The model is based on a series of multiplicative factors: 


$$
\begin{aligned}
\dot{Q}_{\text {peak }}= & \text { (mass factor }) \\
& x \text { (frame factor }) \\
& x \text { (style factor }) \\
& x \text { (padding factor }) \\
& x \text { (fabric factor })
\end{aligned}
$$

The factors are computed as follows:

$$
\begin{aligned}
\text { Mass Factor } & =64 . x \text { (total mass, } \mathrm{kg}) \\
\text { Frame Factor } & = \begin{cases}1.0 & \text { for wood } \\
0.6 & \text { for (rigid) polyurethane foam } \\
2.0 & \text { for (thermoplastic) polypropylene foam }\end{cases} \\
\text { Style Factor } & = \begin{cases}1.0 & \text { for plain, primarily rectilinear construction } \\
1.5 & \text { for ornate, convoluted shapes } \\
\text { with intermediate values for intermediate shapes }\end{cases} \\
\text { Padding Factor } & = \begin{cases}1.0 \text { for polyurethane foam, ordinary or California } \\
0.4 \text { for cotton batting } \\
1.0 \text { for mixed materials filling } \\
0.4 \text { for polychloroprene foam* }\end{cases} \\
\text { Fabric Factor } & = \begin{cases}1.0 & \text { for thermoplastic fabrics (fabrics such as } \\
0.4 & \text { for cellulosic fabrics (cotton; also rayon, } \\
0.25 & \text { for pVC/PU type coverings* }\end{cases}
\end{aligned}
$$

* Estimate based on extrapolation from earlier work [24]. This value would also be applicable to the best available highly retardant treated polyurethane foams but in practice this distinction cannot be made without detailed testing.

**This is an extension based on recent unpublished work. Into this group of coverings are placed those which have a thick layer of polyvinylchloride (PVC) or polyurethane (PU) material supported on a fabric scrim. The construction is often found in washable waiting room chairs and in imitation leather chairs. 
The estimated $\dot{Q}_{\text {peak }}$ has units of $\mathrm{kW}$. Computations for the test specimens are given in table 11. Figure 19 shows the agreement between actual and estimated values.

Time to peak can also be estimated. Here, however, it is important to emphasize the role of the ignition source. Most upholstered furniture items, if successfully and fully ignited, will show [5] approximately similar peak characteristics, although their times to reach the peak may be greatly varied. The ignition source chosen in the present series probably approaches the shortest possible limit, without dominating the furniture fire itself. Times from ignition to peak for most other sources would tend to be 1 onger. Based on these considerations, we can provide an estimate for minimum times to reach peak burning rate:

$$
\begin{aligned}
\text { Minimum time to peak } & \doteq 250 \mathrm{~s} \text { for polyurethane foam with } \\
& \text { thermoplastic fabric } \\
\doteq & 900 \mathrm{~s} \text { for cotton batting with cotton fabric } \\
\doteq & 550 \mathrm{~s} \text { for all others }
\end{aligned}
$$

In addition to the limitations discussed above - - that approximate rules of this nature are only useful for surveying and not for product acceptance -the limited range of materials used must be emphasized. No data were gathered on cotton/thermoplastic blend fabrics, on vinyl coverings, or numerous other less common classes of upholstery materials. Also, consideration was only given to furniture built with a traditional frame, although not necessarily of traditional materials. Some modern furniture does not have a proper frame and earlier test experience has shown [5] that there is little commonality of fire behavior among such specimens.

\section{ON ACHIEVING BOTH CIGARETTE IGNITION RESISTANCE AND GOOD FLAMING BEHAVIOR}

From furniture cigarette ignitability tests, it is seen that cellulosic fabrics perform generally less well than thermoplastic ones and that polyurethane foams might be preferred because, unlike cotton batting they do not have to be specially treated to achieve cigarette ignition resistance. Thus, while at first glance cigarette resistance and good flaming behavior might seen antagonistic goals, this need not be the case. Some readily available materials are known to perform well in both cases - wool fabric and polychloroprene foams are such examples. Both of these have the drawback of being relatively costly. 
It is also very likely that designs can be worked out which combine materials of modest cost in such a way as to achicve good overall performance for both cigarette ignition and flaming situations. Polyurethane foams are, for various manufacturing reasons, much preferred in the furniture industry. It has been shown [24] that it is possible to produce highly fire retardant treated polyurethane foams that have performance similar to polychloroprene. Unfortunately, costs and foam density are also comparable. A more fruitful approach is to protect polyurethane foams with an interliner. Polychloroprene interliners intended for this use have recently come on the market. While this does not reduce the fuel load, it can delay fire development and reduce peak burning rates. When a heavy cellulosic fabric is used on polyurethane foam, it burns slowly when subjected to flames and does not expose the foam itself to flames for some time; however, it is difficult to achieve cigarette ignition resistance with a heavy cellulosic fabric. On the other hand, it was seen in the present test series that common thermoplastic fabrics tend to melt quickly when exposed to heat. Thus, they expose the foam to rapid heating from flames and from radiation early in the fire. An interliner may only provide a modest additional benefit when used under a cellulosic fabric but can be of significant benefit under a thermoplastic one. The use of some early polychloroprene-based interliners has been studied [5,24]. An extensive testing program in Great Britain resulted in recommendation for the use of cotton cambric as an interliner [25]. Additional cigarette resistance can be imparted to such a cambric by bonded aluminized and thermoplastic layers, as has been done in experimental systems.

For the choice of fabrics, additional investigation is likely to show modestly priced types that can have both smolder resistance and good resistance to rapid flame propagation. Since poor flaming condition behavior is largely attributed to the fabric melting away and opening up quickly, charring fiber materials, such as modacrylics and matrix fabrics, should be investigated.

\section{SUMMARY AND CONCLUSIONS}

The advantages of open - - as opposed to room - - fire testing were considered and were shown to motivate the construction of a furniture calorimeter.

A description was provided of the design of a full-scale furniture calorimeter for making burning rate measurements. An oxygen consumption technique was used to measure heat release, and conventional instruments were used for measurement of mass loss, smoke production and target irradiance. 
The primary effort was addressed to gathering comparative open flame burning rate data on a set of upholstered furniture pieces where only one construction feature was varied at a time. The findings showed that for the range of constructions examined:

a - Furniture using polyurethane foams with retardants added to meet California state requirements did not show any reduction in rate of heat release compared to ordinary polyurethane foams. (This finding was earlier noted in bench-scale tests by Herrington [26].

b - For foam-padded chairs, rate of heat release was related to specimen mass - - for comparable specimens, those that weighed more showed higher rates of heat release. This indicates that any realistic testing or evaluation procedure must take specimen mass into account and cannot be based on smallscale tests alone.

c - Furniture using padding materials made of cotton batting showed lower rates of heat release and slower fire buildup than those using polyurethane foams or battings of mixed fibers.

d - - Furniture using cellulosic fabrics showed lower rates of heat release and slower fire buildup than those using thermoplastic fabrics. Cellulosic/thermoplastic blends were not investigated.

e -- Structural foam frames showed widely differing behaviors. A frame of a charring plastic was seen to give a lower heat release rate than a wood frame, while a melting, thermoplastic frame material led to a substantially greater heat release.

f - Furniture items with more polymeric content showed significantly more smokiness than those with primarily cellulosic content. Since the total smoke production rate is the product of the smokiness times the burning rate, the total release of smoke for predominantly polymeric specimens was considerably greater.

g - - A very approximate set of rules was suggested for estimating the rate of heat release of upholstered furniture based only on known weights and construction. This can be useful in hazards surveying work. 
Further quantification of the burning rates of upholstered furniture will be carried on in three directions: (1) burning of simplified mock-ups in the furniture calorimeter; (2) rate of heat release tests on small specimens cut from test chairs; and (3) the development of a laboratory flame spread test suitable for testing upholstered furniture samples. The eventual development of a test protocol is then cnvisioned which will enable the relative fire risk of furniture items to be quantified using actual measured properties.

Finally, it is emphasized that limited heat release during flaming exposure and good cigarette ignition resistance are not necessarily mutually exclusive and that reasonable designs can be cvolved suited to both.

\section{ACKNOWLEDGEMENTS}

David E. Swanson participated in the construction of the calorimeter; Charles F. Veirtz assisted in the operation; David P. Klein provided computer programming assistance.

The project was part 1 y funded by the Consumer Product Safety Commission as Project 154, Paul Lancer, technical monitor. The development of the furniture calorimeter was also partly funded through the Department of Health and Human Services, Jonas Morehart, project officer.

\section{REFERENCES}

(1) Pape, R., Waterman, T.E., Understanding and modeling preflashover compartment fires, Design of Buildings for Fire Safety (ASTM STP 685), pp 106-138, E.E. Smith, T.Z. Harmathy, eds. American Society for Testing and Materials, Philadelphia, PA (1978).

(2) Mitler, H.E., Emmons, H.W., Documentation for CFC-V, The fifth Harvard computer fire code, Nat. Bur. Stand. (U.S.), NBS-GCR-81-344 (1981).

(3) Loftus, J.J., Back-up report for the proposed standard for the flammability (cigarette ignition resistance) of upholstered furniture, PFF676, Nat. Bur. Std. (U.S.), NBSIR 78-1438 (1978).

(4) Pape, R., et a1., Semistochastic approach to predicting the development of a fire in room from ignition to flashover. Program documentation and users guide, RFIRES. IIT Research Institute, Chicago (1976). NTIS No. PB-278643.

(5) Babrauskas, V., Ful1-scale burning behavior of upholstered chairs, Nat. Bur. Std. (U.S.) Tech. Note 1103 (1979).

(6) Bard, S., Clow, K.H., Pagni, P.J., Combustion of Cellular Urethane, Combustion Science and Technology. 19, 141-150 (1979).

(7) Babrauskas, V., Will the second item ignite? Fire Safety J. (1982).

(8) Gross, D., Ward, D., Shoub, H., Fires in model rooms. Results of preliminary experiments under an international cooperative program, Nat. Bur. Std. (U.S.), unpublished report (1960). 
(9) Tewarson, A., Some observations on experimental fires in enclosures, Part I, cellulosic materials; Part II, alcohol and paraffin oil.

Factory Mutual Research Corp., Norwood, MA (1971).

(10) Croce, P.A., Modeling of vented enclosure fires, pp 23-37, vol. 1, Fifth International Fire Protection Seminar, Karlsruhe, Germany (1976).

(11) Quintiere, J.G., Rinkinen, W.J., Jones, W.W., The effect of room openings on fire plume entrainment, Combustion Science and Technology. 26, 193201 (1981).

(12) Babrauskas, V., Estimating room flashover potential, Fire Technology. 16, $94-103,112(1980)$.

(13) Tu, K-M., Babrauskas, V., The calibration of a burn room for fire tests on furnishings, Nat. Bur. Std. (U.S.) Tech. Note 981 (1978).

(14) Huggett, C., Estimation of rate of heat release by means of oxygen consumption measurements, Fire and Materials. 4 , 61-5 (1980).

(15) Parker, W.J., Calculations of the heat release rate by oxygen consumption for various applications, Nat. Bur. Std. (U.S.), NBSIR 81-2427 (1982).

(16) Babrauskas, V., Combustion of mattresses exposed to flaming ignition sources, part I. Ful1-scale tests and hazard analysis, Nat. Bur. Std. (U.S.) NBSIR 77-1290 (1977).

(17) Croce, P.A., A method for improved measurement of gas concentration histories in rapidly developing fires, Combustion Science and Technology, $14,221-228(1976)$.

(18) Evans, D.D., Breden, L.H., A numerical technique to correct heat release rate calorimetry data for apparatus delay, Nat. Bur. Std. (U.S.) NBSIR 77-1302 (1977).

(19) Bukowski, R.W., Smoke measurements in large- and sma11-scale fire testing, Fire Technology. 15, 173-9, 271-281 (1979).

(20) Babrauskas, V., Applications of predictive smoke measurements, J. Fire and Flammability. 12, 51-64 (1981).

(21) Requirements, test procedure and apparatus for testing the flame retardance of resilient filling materials used in upholstered furniture (Technical Information Bulletin 117). State of California Department of Consumer Affairs, Bureau of Home Furnishings, Sacramento (January 1980).

(22) Fire Protection Handbook, p 4-122, National Fire Protection Assn., Quincy, MA (1981).

(23) Modak, A.T., Thermal radiation from pool fires, Combustion and Flame. 29, $177-192(1977)$.

(24) Babrauskas, V., Combustion of mattresses exposed to flaming ignition sources, Part II. Benchscale tests and hazard analysis, Nat. Bur. Std. (U.S.) NBSIR $80-2186$ (1981).

(25) Fire research on cellular plastics: The final report of the Products Research Committee, Washington, D.C. (1980).

(26) Herrington, R.M., The rate of heat, smoke and toxic gases release from polyurethane foams, J. Fire and Flammability. 10, 308-325 (1979). 
(27) Friedlander, S.K., Smoke, Dust and Haze, Wiley, New York (1977).

(28) Bankston, C.P., et al., Review of Smoke Particulate Properties Data for Burning Natural and Synthetic Materials, Georgia Institute of Technology (1978). NTIS No. PB-292066.

(29) Liu, B.Y.H., Ilori, T.A., Aerosol Deposition in Turbulent Pipe Flow, Environmental Science and Technology, Vol. 8, 351-356 (1974).

(30) Standard Test Method for Specific Optical Density of Smoke Generated by Solid Materials (ANSI/ASTM E662). American Society for Testing and Materials, Philadelphia, PA. 


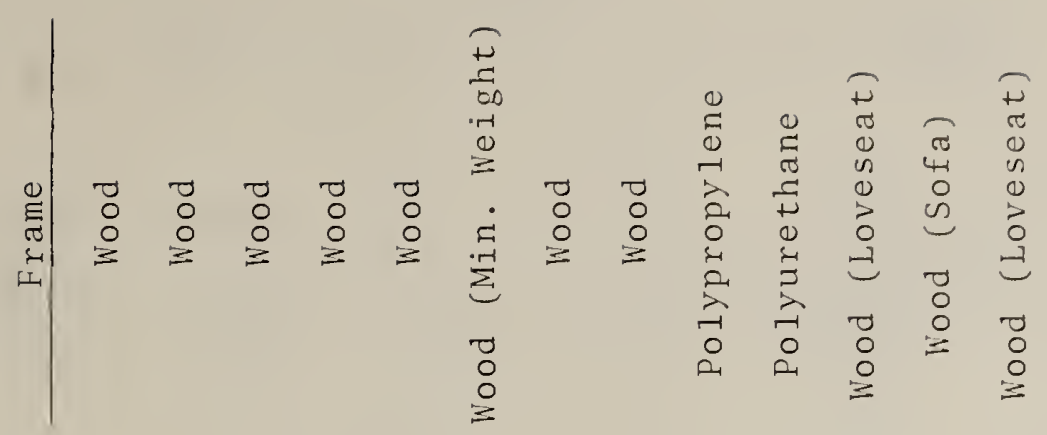

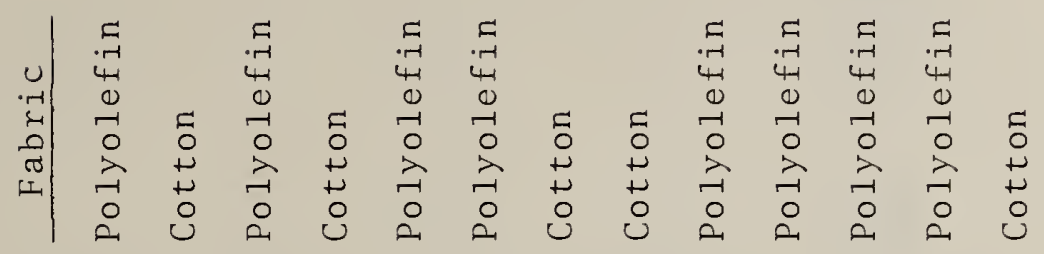

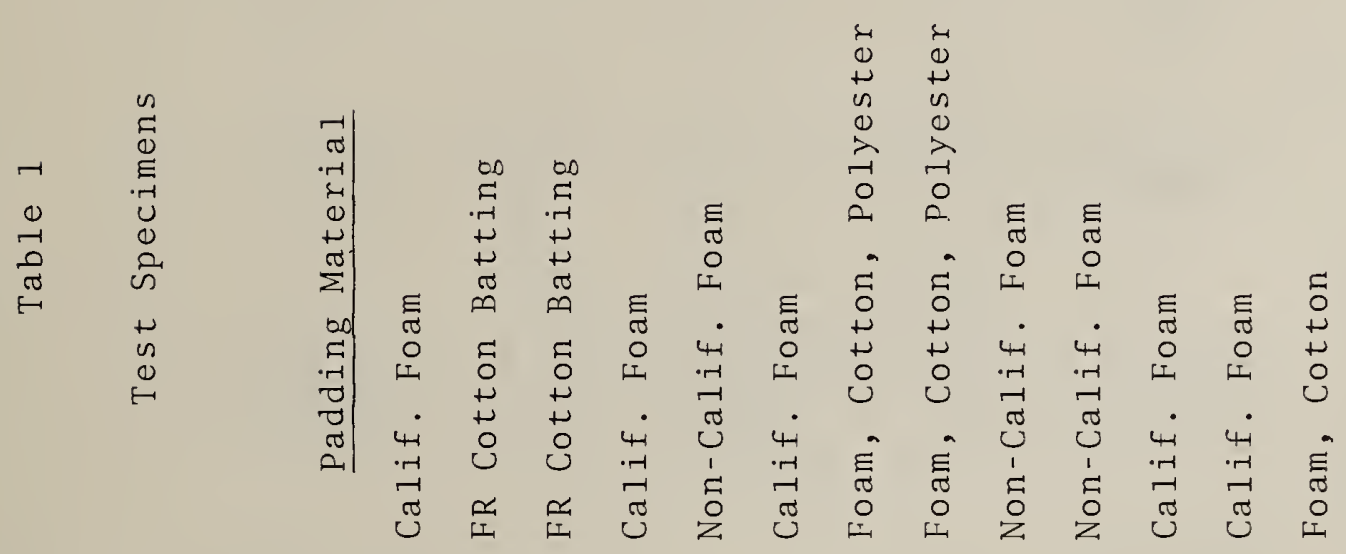

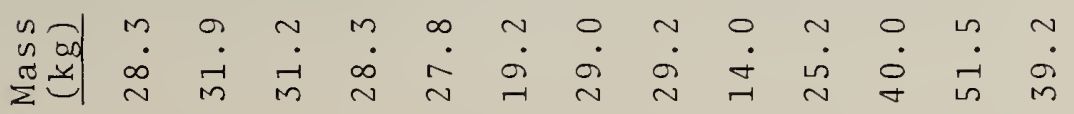

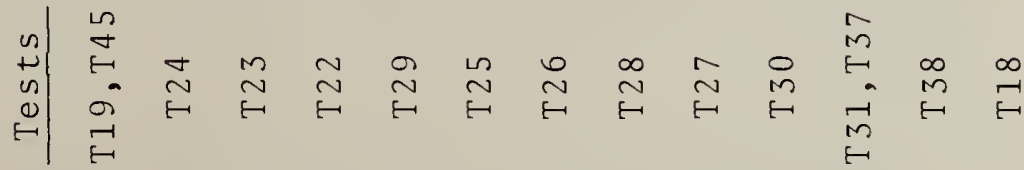

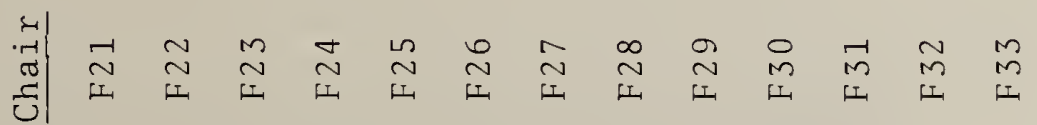




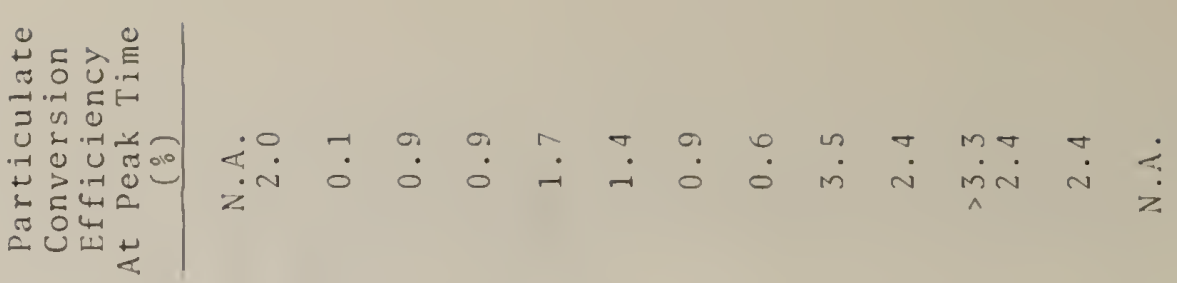

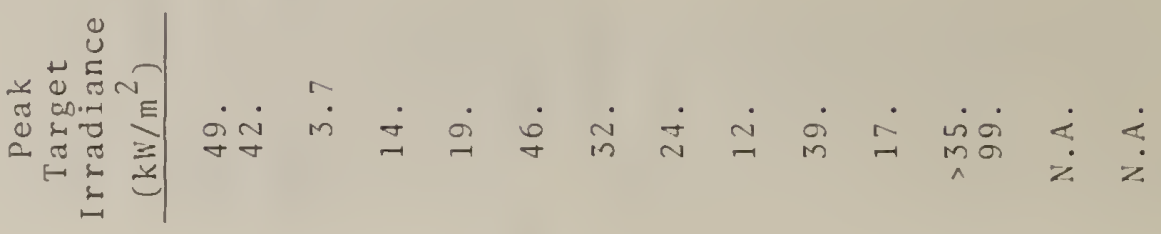

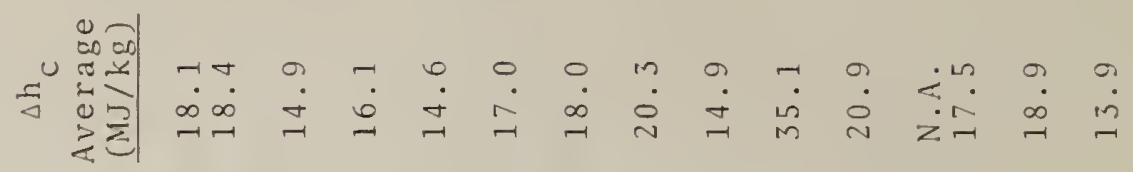

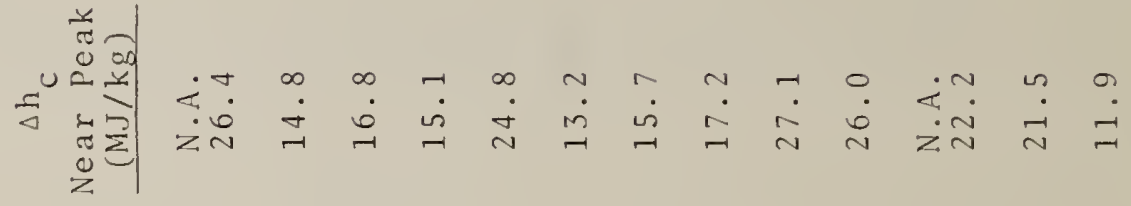

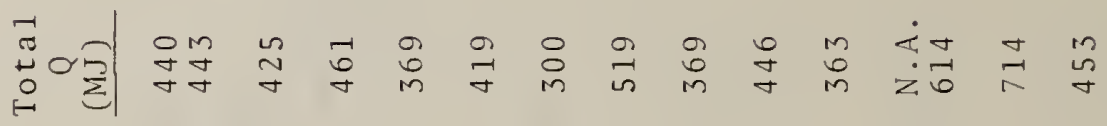

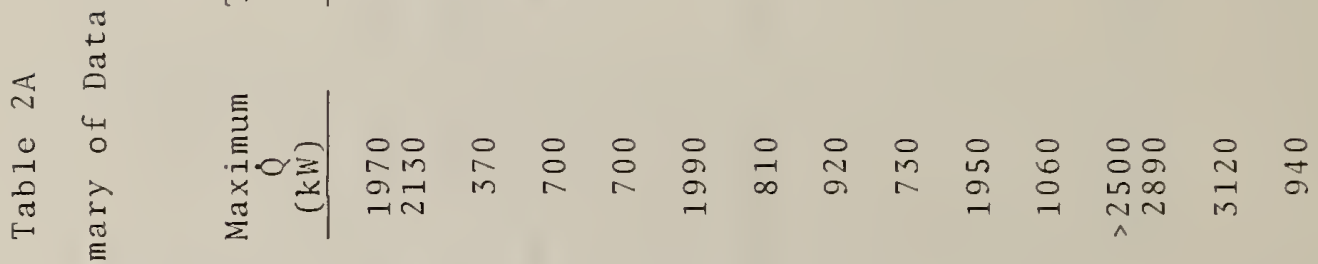

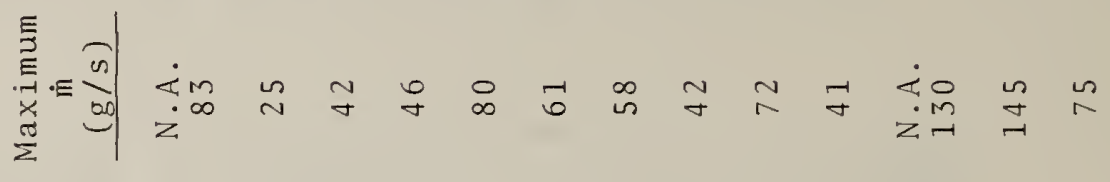

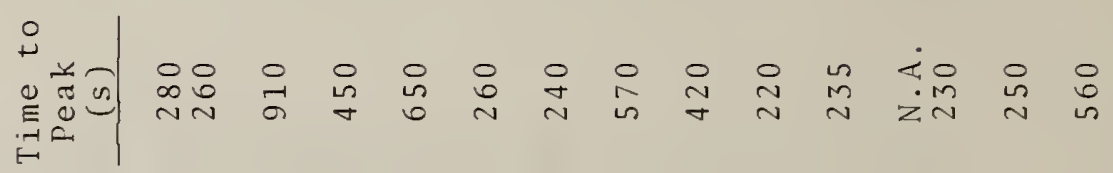

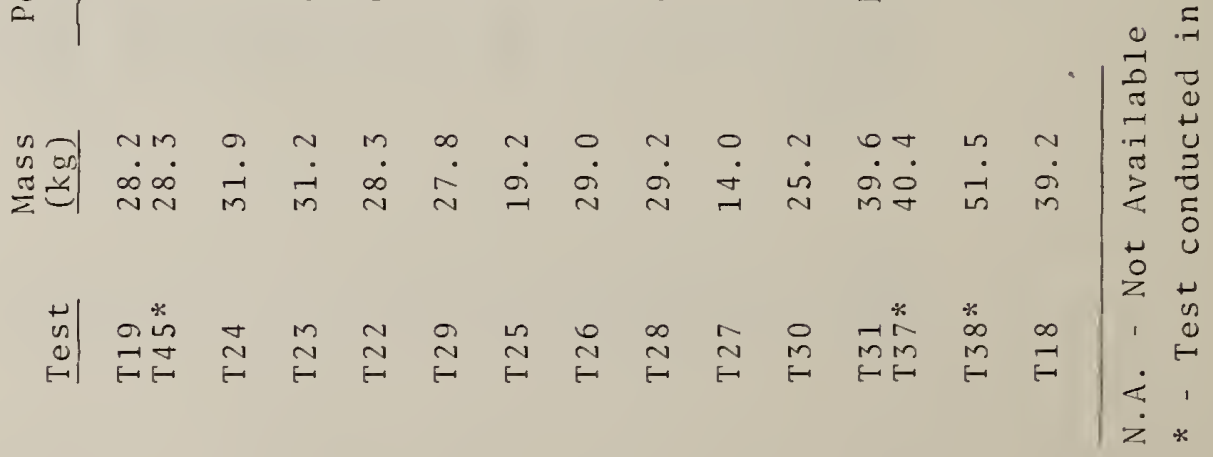

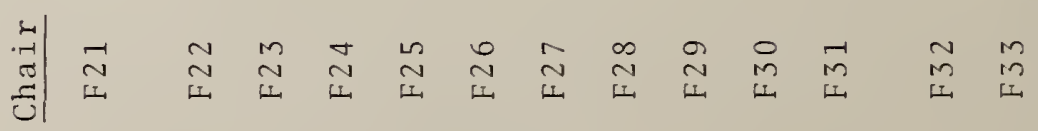


Table 2B

Supplementary Data - Values at Peak

\begin{tabular}{|c|c|c|c|c|c|}
\hline Specimen & Test & $\begin{array}{l}\mathrm{O}_{2} \\
(\%) \\
\end{array}$ & $\begin{array}{l}\mathrm{CO}_{2} \\
(\%) \\
\end{array}$ & $\begin{array}{l}\mathrm{CO} \\
\left(\frac{0}{0}\right) \\
\end{array}$ & $\begin{array}{c}\dot{\mathrm{m}} \\
\mathrm{a} \\
(\mathrm{kg} / \mathrm{s}) \\
\end{array}$ \\
\hline F 21 & $\begin{array}{l}\text { T19 } \\
\text { T45* }\end{array}$ & $\begin{array}{r}7.54 \\
17.31\end{array}$ & $\begin{array}{r}10.51 \\
2.85\end{array}$ & $\begin{array}{c}0.11 \\
<0.001\end{array}$ & $\begin{array}{l}1.07 \\
3.84\end{array}$ \\
\hline F 22 & T 24 & 19.65 & 0.64 & $<0.001$ & 1.82 \\
\hline F 23 & T23 & 17.12 & 3.27 & 0.015 & 1.27 \\
\hline F 24 & T 22 & 17.23 & 3.52 & $<0.001$ & 1.33 \\
\hline F 25 & T29 & 7.80 & 7.06 & 0.12 & 1.08 \\
\hline F 26 & T25 & 16.93 & 3.95 & $<0.001$ & 1.44 \\
\hline F 27 & T 27 & 15.45 & 4.49 & $<0.001$ & 1.16 \\
\hline F 28 & T28 & 17.47 & 2.57 & $<0.001$ & 1.42 \\
\hline F 29 & T27 & 5.12 & 11.35 & 0.46 & 0.88 \\
\hline F 30 & T30 & 15.53 & 2.38 & 0.06 & 1.28 \\
\hline F 31 & $\begin{array}{l}\text { T31 } \\
\text { T37 * }\end{array}$ & $\begin{array}{l}\text { N.A. } \\
16.02\end{array}$ & $\begin{array}{l}\text { N.A. } \\
3.86\end{array}$ & $\begin{array}{l}\text { N.A. } \\
0.11\end{array}$ & $\begin{array}{l}\text { N.A. } \\
4.06\end{array}$ \\
\hline F 32 & T $38 *$ & 16.06 & 3.81 & 0.12 & 4.42 \\
\hline F 33 & T18 & 12.78 & 7.22 & 0.06 & 0.84 \\
\hline
\end{tabular}

N.A. - Not available

* - Test conducted in large test rig. 


\section{Ranked Peak Times}

\begin{tabular}{|c|c|c|c|}
\hline specimen & $\begin{array}{ll}\text { Time to } \\
\text { Peak (s) } \\
\end{array}$ & Padding & Fabric \\
\hline F 22 & 910 & Cotton & Cotton \\
\hline F 24 & 650 & PU Foam, C* & Cotton \\
\hline $\mathrm{F} 27$ & 570 & Mixed & Cotton \\
\hline F 33 & 560 & Mixed & Cotton \\
\hline F 23 & 450 & Cotton & Polyolefin \\
\hline F 28 & 420 & Mixed & Cotton \\
\hline F 21 & 280 & PU Foam, C & Polyolefin \\
\hline F 25 & 260 & PU Foam, NC & Polyolefin \\
\hline F 32 & 250 & PU Foam, C & Polyolefin \\
\hline F 26 & 240 & PU Foam, C & Polyolefin \\
\hline F 30 & 235 & PU Foam, NC & Polyolefin \\
\hline F 31 & 230 & PU Foam, C & Polyolefin \\
\hline F 29 & 220 & PU Foam, NC & Polyolefin \\
\hline
\end{tabular}

*PU $=$ Polyurethane $; C=$ California Foam;

$\mathrm{NC}=$ Not California Foam 
Table 4

Ranked Peak Heat Release Values

\begin{tabular}{|c|c|c|c|}
\hline Specimen & $\begin{array}{l}\text { Peak Q } \\
(\mathrm{kW}) \\
\end{array}$ & Padding & Fabric \\
\hline F 22 & 3705 & Cotton & Cotton \\
\hline F 24 & 700 & PU Foam, C* & Cotton \\
\hline F 23 & 700 & Cotton & Polyolefin \\
\hline F 28 & 730 & Mixed & Cotton \\
\hline F26 & 810 & PU Foam, C & Polyolefin \\
\hline $\mathrm{F} 27$ & 920 & Mixed & Cotton \\
\hline F 33 & 940 & Mixed & Cotton \\
\hline F 30 & 1060 & PU Foam, NC & Polyolefin \\
\hline F 29 & 1950 & PU Foam, NC & Polyolefin \\
\hline $\mathrm{F} 21$ & 1970 & PU Foam, C & Polyolefin \\
\hline F 25 & 1990 & PU Foam, NC & Polyolefin \\
\hline F 31 & 2890 & PU Foam, C & Polyolefin \\
\hline F 32 & 3120 & PU Foam, C & Polyolefin \\
\hline $\begin{array}{l}\overline{\mathrm{PU}}=\mathrm{PC} \\
\mathrm{NC}=\mathrm{NC}\end{array}$ & thano & $\begin{array}{l}\text { California } \\
\text { am }\end{array}$ & \\
\hline
\end{tabular}




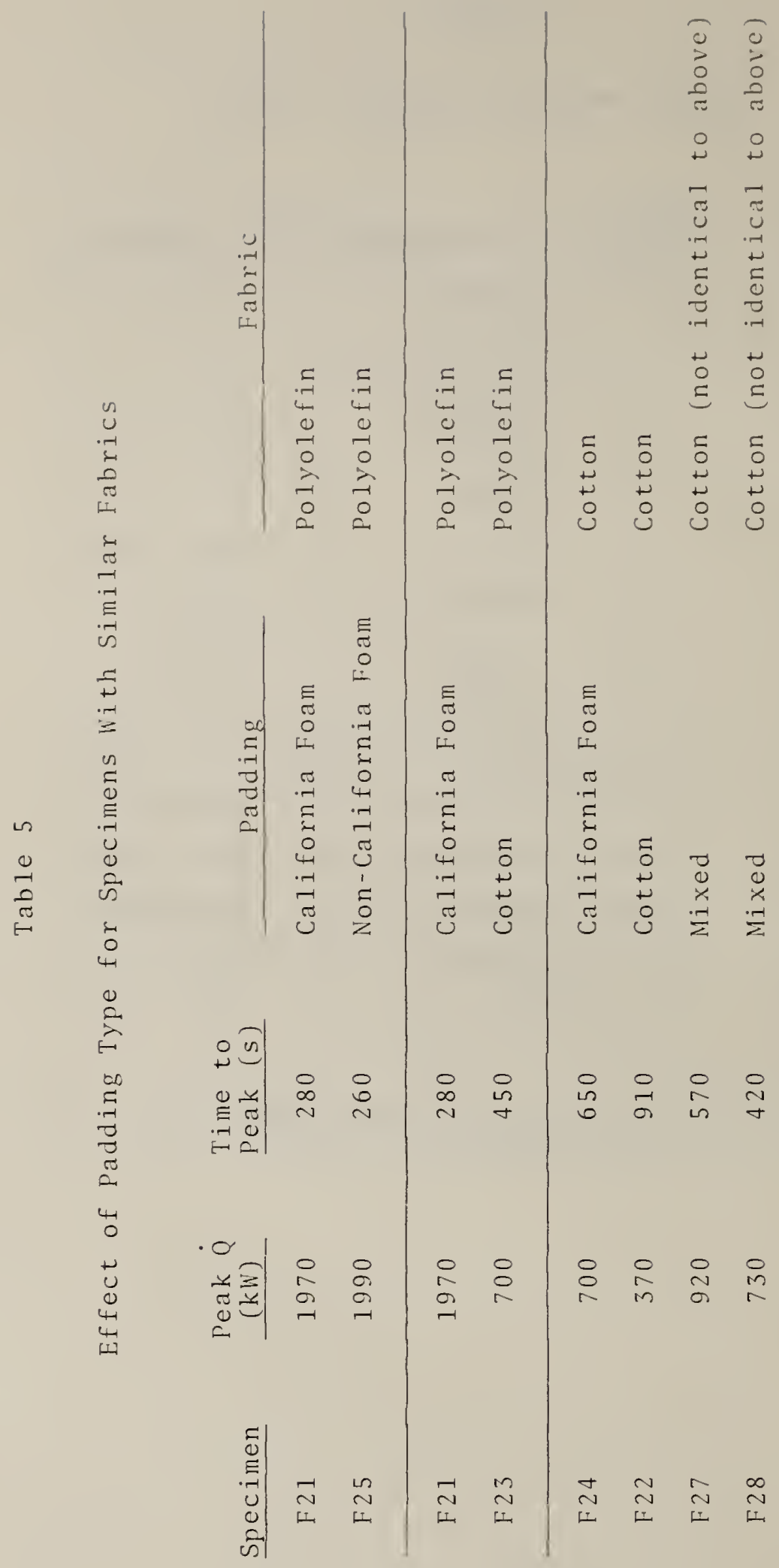


Table 6

Effect of Fabric Type for Specimens of Similar Construction and Padding

\begin{tabular}{|c|c|c|c|c|}
\hline Specimen & $\begin{array}{l}\text { Peak Q } \\
(\mathrm{kW}) \\
\end{array}$ & $\begin{array}{l}\text { Time to } \\
\text { Peak (s) }\end{array}$ & Fabric & Padding \\
\hline F24 & 700 & 650 & Cotton & California Foam \\
\hline F 21 & 1970 & 280 & Polyolefin & California Foam \\
\hline F 22 & 370 & 910 & Cotton & Cotton \\
\hline F23 & 700 & 450 & Polyolefin & Cotton \\
\hline
\end{tabular}

Table 7

Effect of Specimen Mass on Polyurethane Foam

Padded Specimens of Similar Construction

\begin{tabular}{|c|c|c|c|c|}
\hline Specimen & $\begin{array}{c}\text { Peak ? } \\
(\mathrm{kW}) \\
\end{array}$ & $\begin{array}{l}\text { Time to } \\
\text { Peak (s) } \\
\end{array}$ & $\begin{array}{r}\text { Mass } \\
(\mathrm{kg}) \\
\end{array}$ & Comments \\
\hline F26 & 810 & 240 & 19.2 & Minimum Weight Chair \\
\hline F21 & 1970 & 280 & 28.2 & Standard Chair \\
\hline F 31 & 2890 & 230 & 40.0 & Loveseat \\
\hline F32 & 3120 & 250 & 51.5 & So fa \\
\hline
\end{tabular}




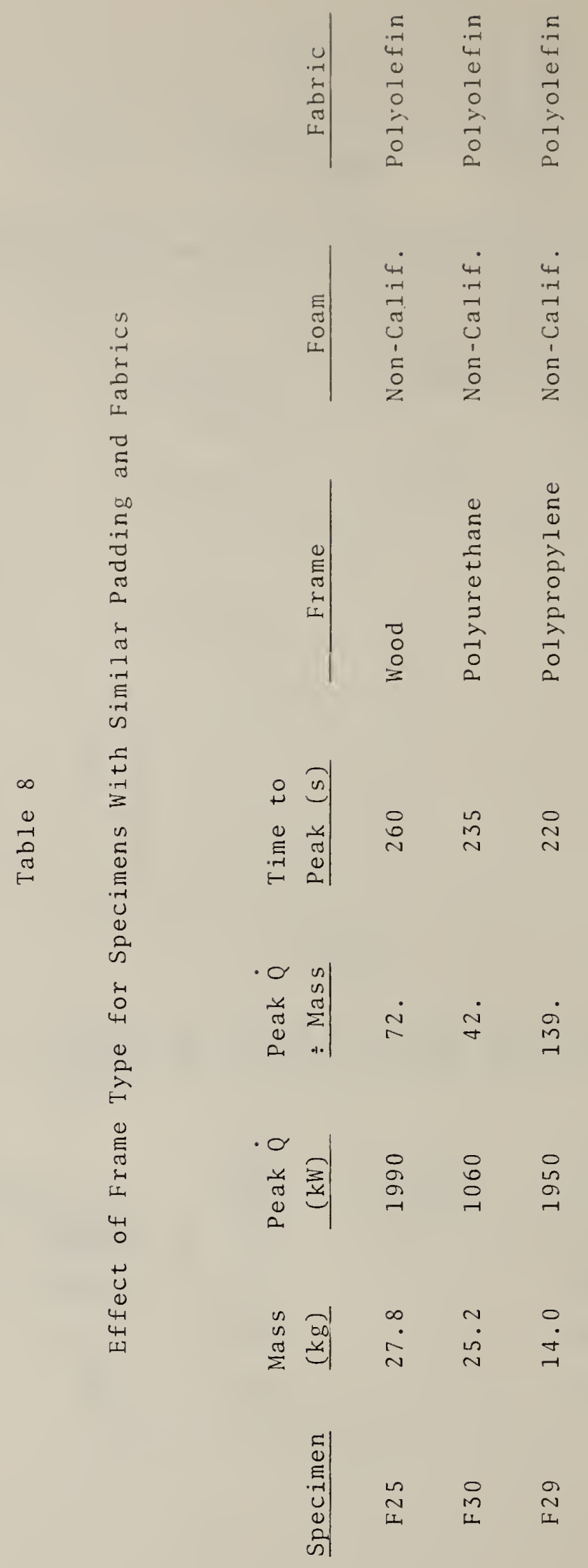




\section{Table 9}

Ranked Values for Smoke

\begin{tabular}{|c|c|c|c|}
\hline Specimen & $\begin{array}{c}\text { Smoke } \\
\text { Particulate } \\
\text { Conversion } \\
\text { Efficiency }(\%)\end{array}$ & Padding & Fabric \\
\hline F 28 & 0.6 & Mixed & Cotton \\
\hline F 23 & 0.9 & Cotton & Polyolefin \\
\hline F 24 & 0.9 & PU Foam, C* & Cotton \\
\hline $\mathrm{F} 27$ & 0.9 & Mixed & Cotton \\
\hline F 26 & 1.4 & PU Foam, C & Polyolefin \\
\hline F 25 & 1.7 & PU Foam, NC & Polyolefin \\
\hline F 21 & 2.0 & PU Foam, C & Polyolefin \\
\hline F 30 & 2.4 & PU Foam, NC & Polyolefin \\
\hline F 31 & 2.4 & PU Foam, C & Polyolefin \\
\hline F 32 & 2.4 & PU Foam, C & Polyolefin \\
\hline F 29 & 3.5 & PU Foam, NC & Polyolefin \\
\hline
\end{tabular}

* PU = Polyurethane; $C=$ California Foam; NC = Not California Foam 

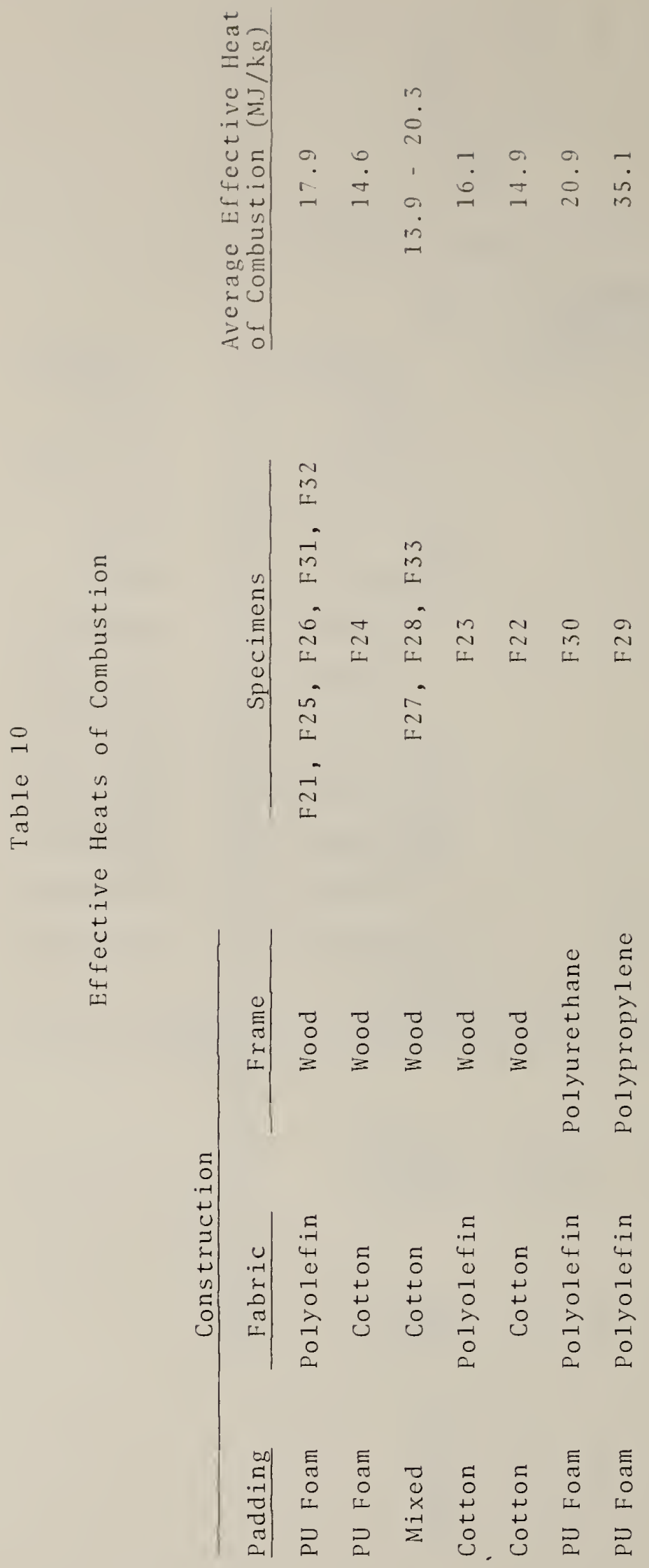
Table 11

Estimated Heat Release Rate Data

\begin{tabular}{|c|c|c|c|c|c|c|c|}
\hline Specimen & $\begin{array}{c}\text { Mass } \\
\text { Factor } \\
\end{array}$ & $\begin{array}{l}\text { Frame } \\
\text { Factor } \\
\end{array}$ & $\begin{array}{l}\text { Style } \\
\text { Factor } \\
\end{array}$ & $\begin{array}{l}\text { Padding } \\
\text { Factor } \\
\end{array}$ & $\begin{array}{l}\text { Fabric } \\
\text { Factor }\end{array}$ & $\begin{array}{c}\text { Estimated } \\
\dot{Q} \\
(\mathrm{~kW}) \\
\end{array}$ & $\begin{array}{c}\text { Me as ured } \\
\dot{Q} \\
(\mathrm{~kW}) \\
\end{array}$ \\
\hline F 21 & 1811 & 1.0 & 1.0 & 1.0 & 1.0 & 1811 & 1970 \\
\hline F 22 & 2042 & 1.0 & 1.0 & 0.4 & 0.4 & 327 & 370 \\
\hline F23 & 1997 & 1.0 & 1.0 & 0.4 & 1.0 & 799 & 700 \\
\hline F 24 & 1811 & 1.0 & 1.0 & 1.0 & 0.4 & 724 & 700 \\
\hline F 25 & 1779 & 1.0 & 1.0 & 1.0 & 1.0 & 1779 & 1990 \\
\hline F 26 & 1229 & 1.0 & I. 0 & 1.0 & 1.0 & 1229 & 810 \\
\hline $\mathrm{F} 27$ & 1856 & 1.0 & 1.2 & 1.0 & 0.4 & 891 & 920 \\
\hline F28 & 1869 & 1.0 & 1.2 & 1.0 & 0.4 & 897 & 730 \\
\hline F 29 & 896 & 2.0 & 1.2 & 1.0 & 1.0 & 2150 & 1950 \\
\hline F 30 & 1613 & 0.6 & 1.2 & 1.0 & 1.0 & 1161 & 1060 \\
\hline F 31 & 2560 & 1.0 & 1.0 & 1.0 & 1.0 & 2560 & 2890 \\
\hline F 32 & 3296 & 1.0 & 1.0 & 1.0 & 1.0 & 3296 & 3120 \\
\hline F 33 & 2509 & 1.0 & 1.0 & 1.0 & 0.4 & 1004 & 940 \\
\hline
\end{tabular}




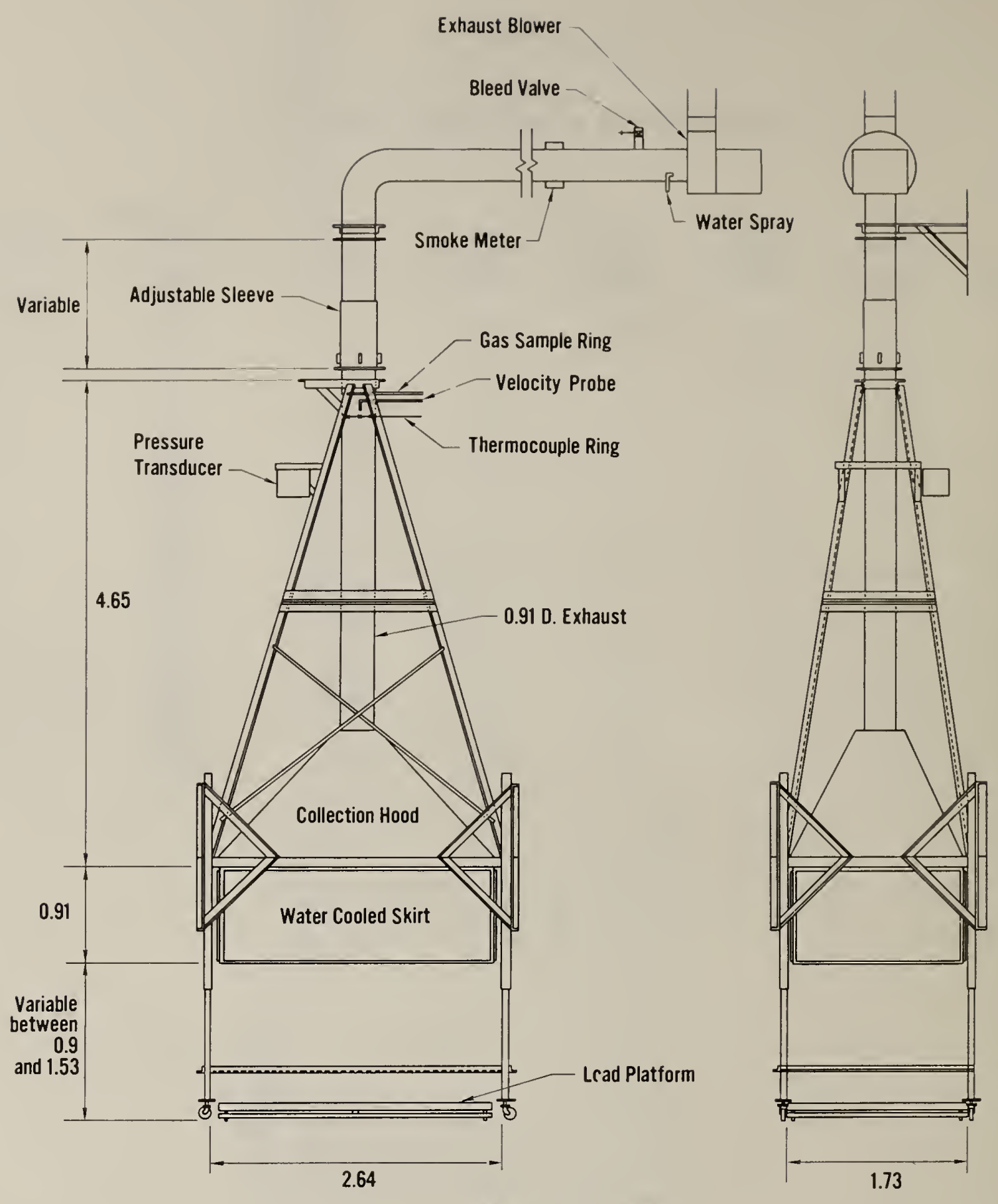

All dimensions in meters

Figure 1. View of furniture calorimeter. 


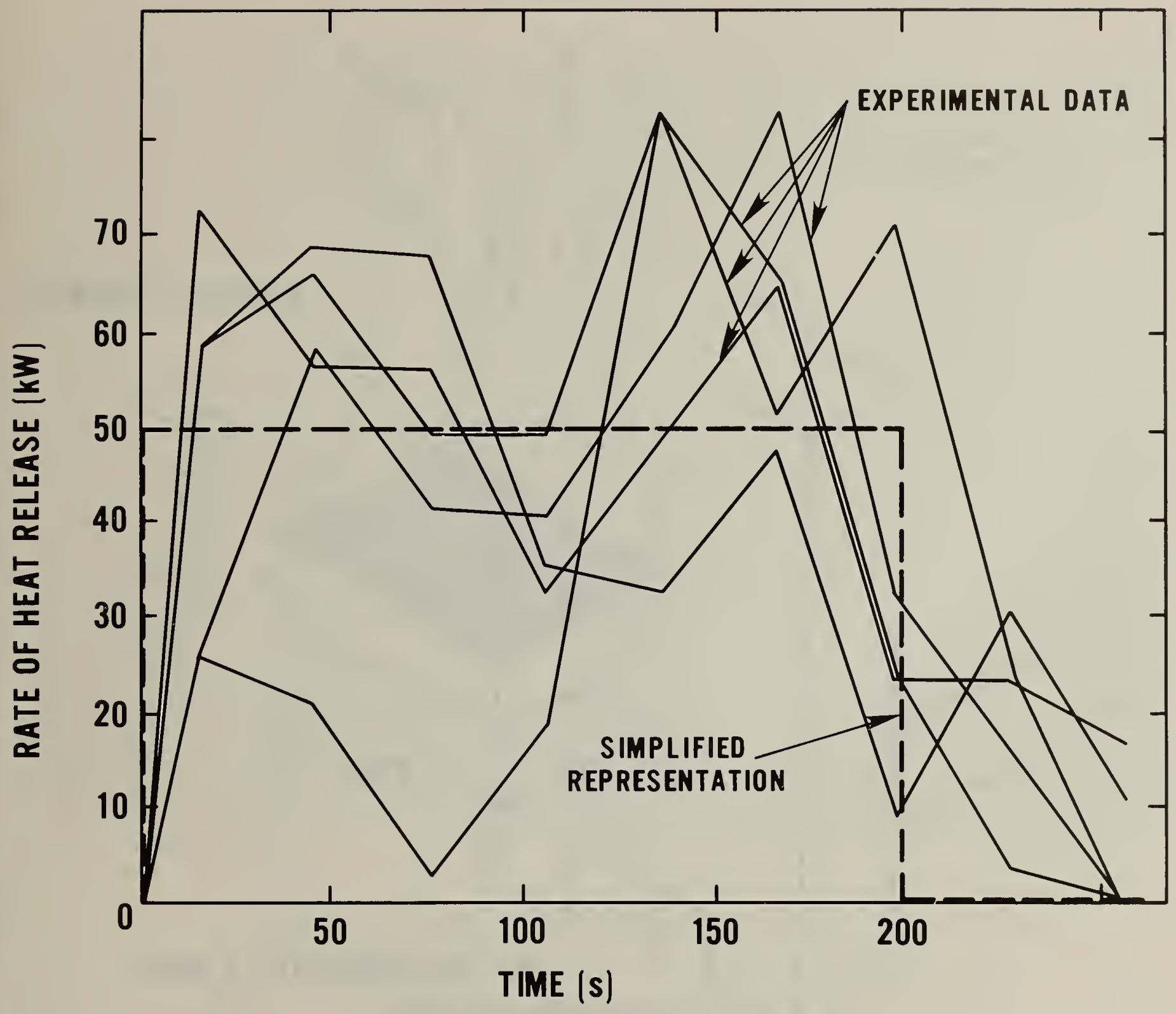

Figure 2. Measured wastebasket heat release rates, along with adopted simplified representation 


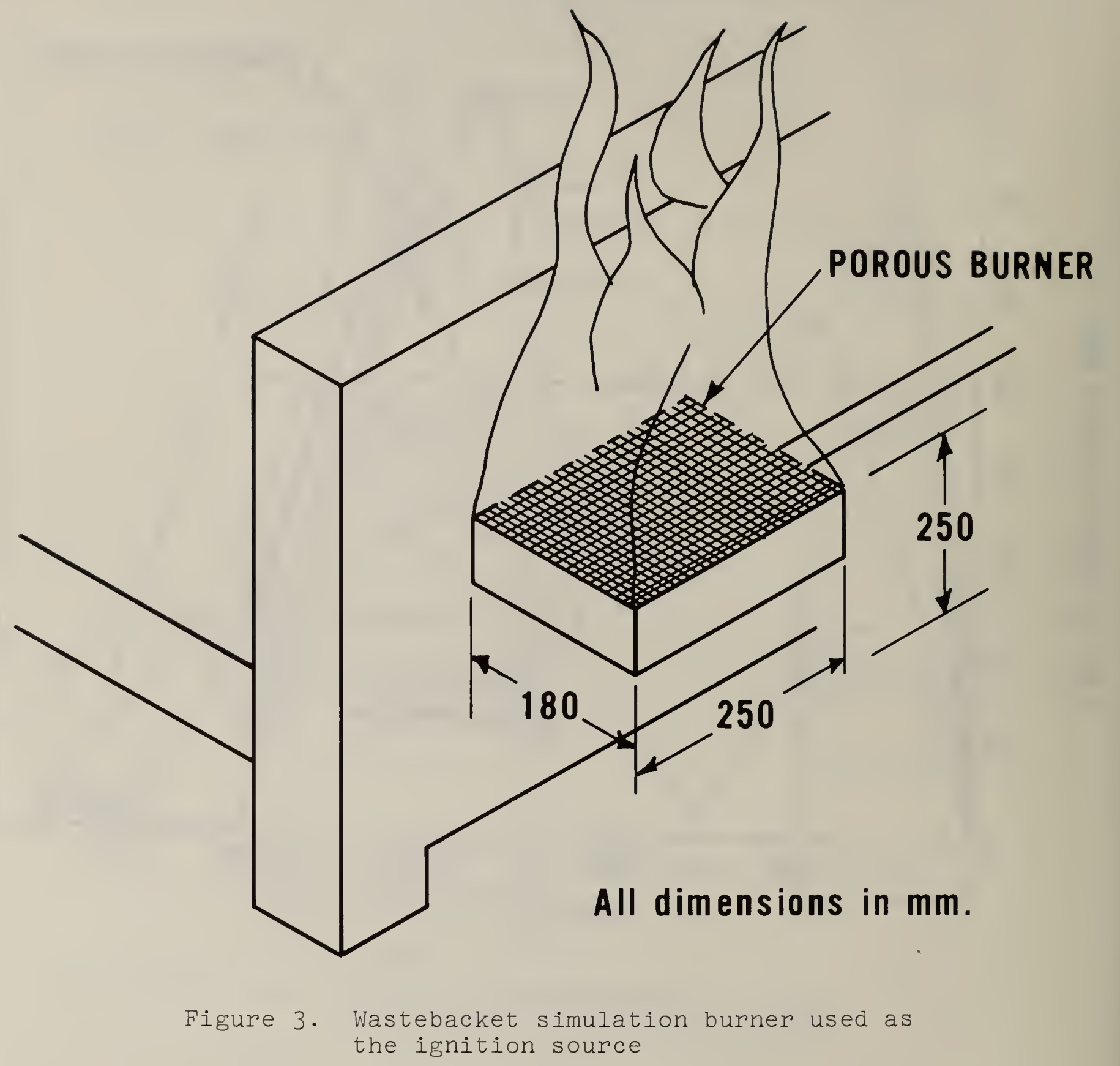




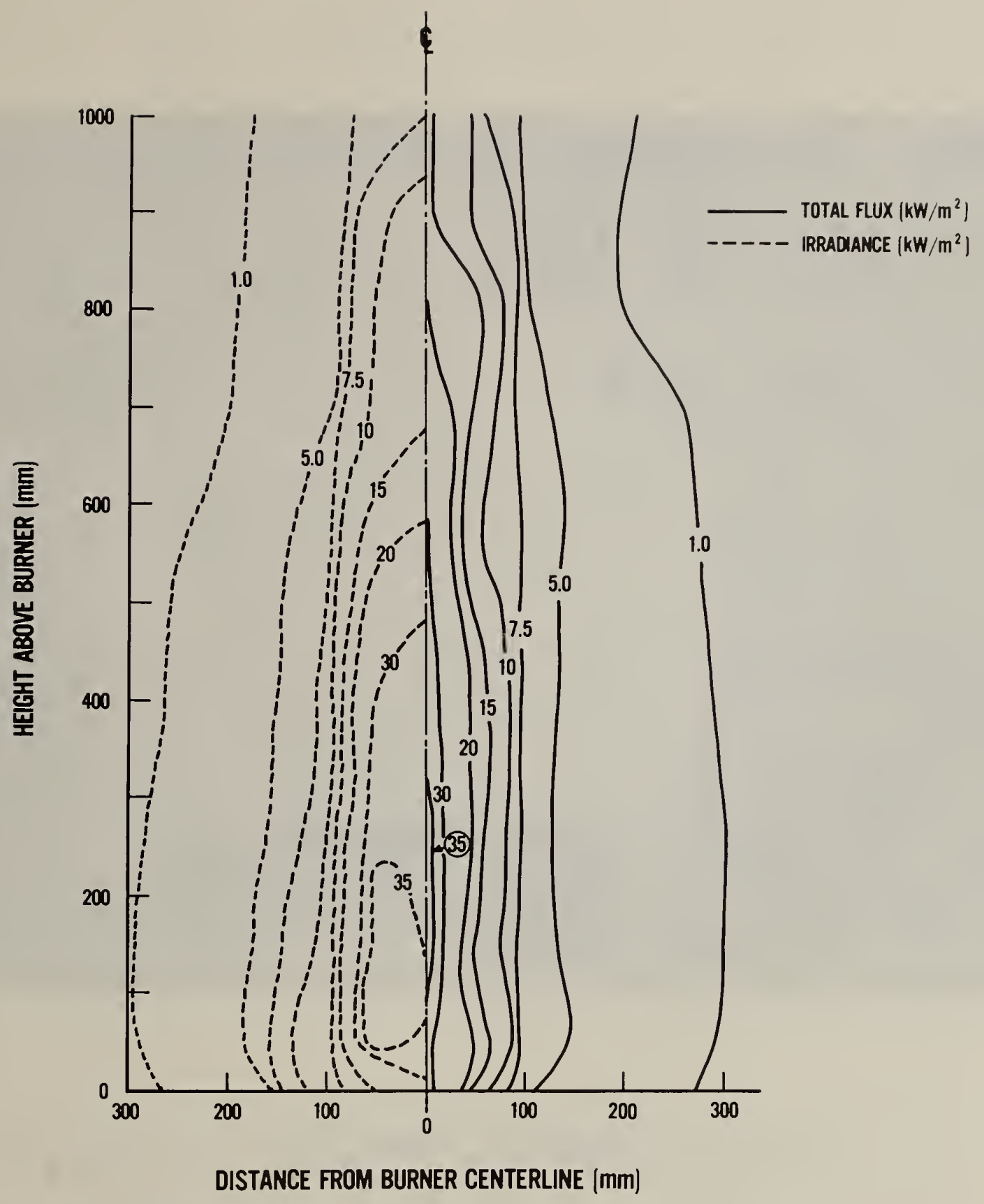

Figure 4. Fluxes measured at the wastebasket simulation burner 


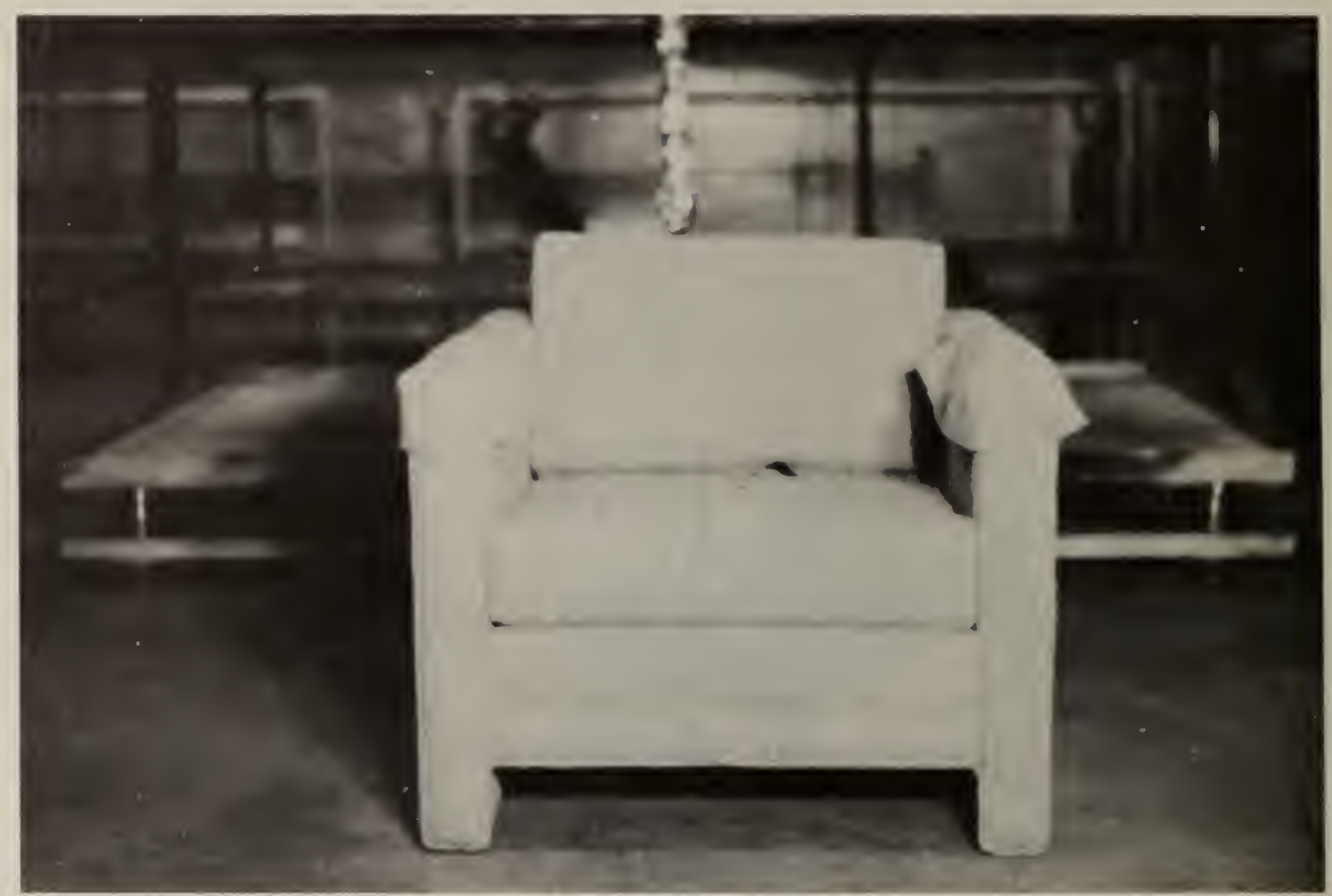

Figure 5. Chair F2I 


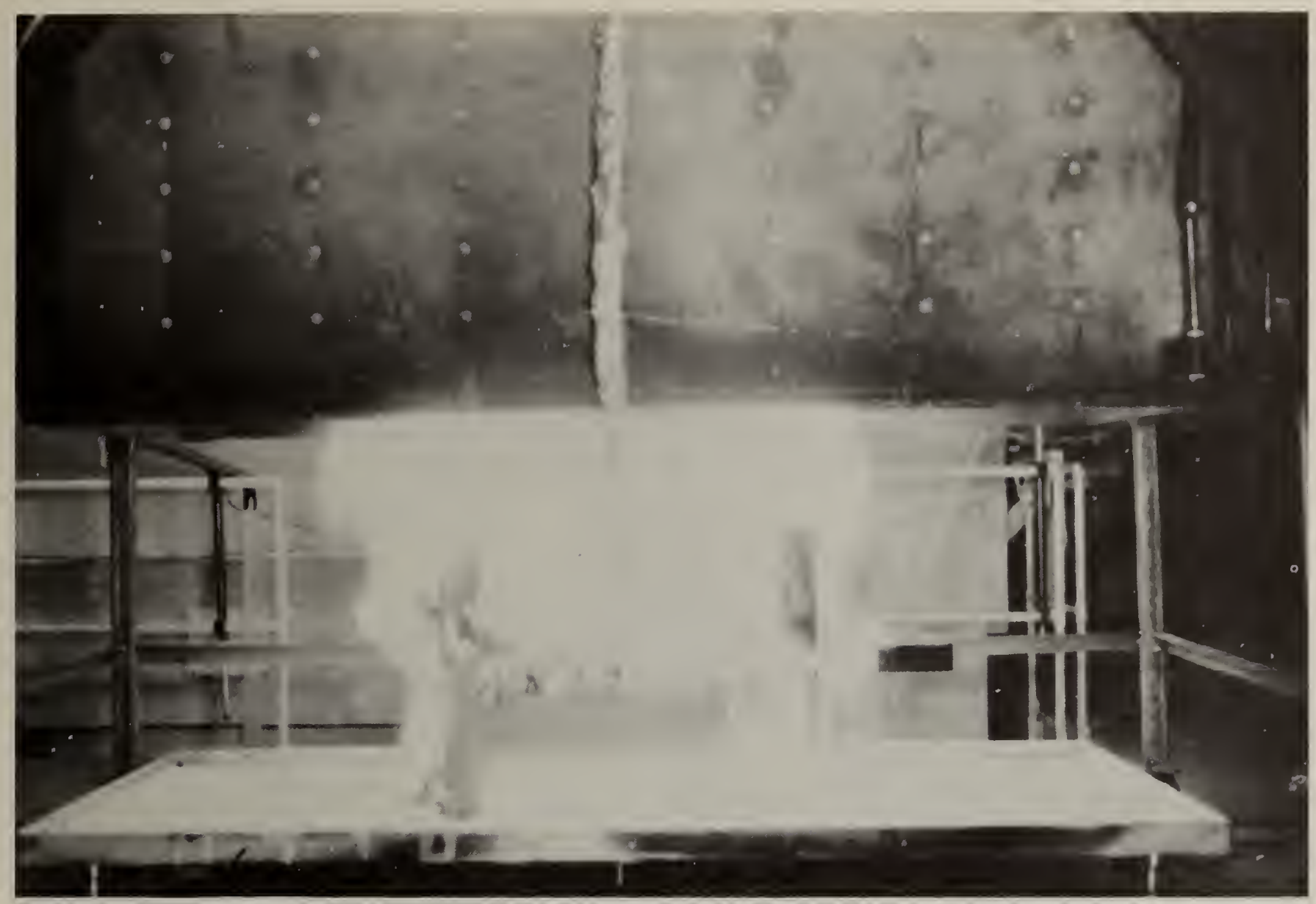

Figure 6. Chair F2l near peak burning time 


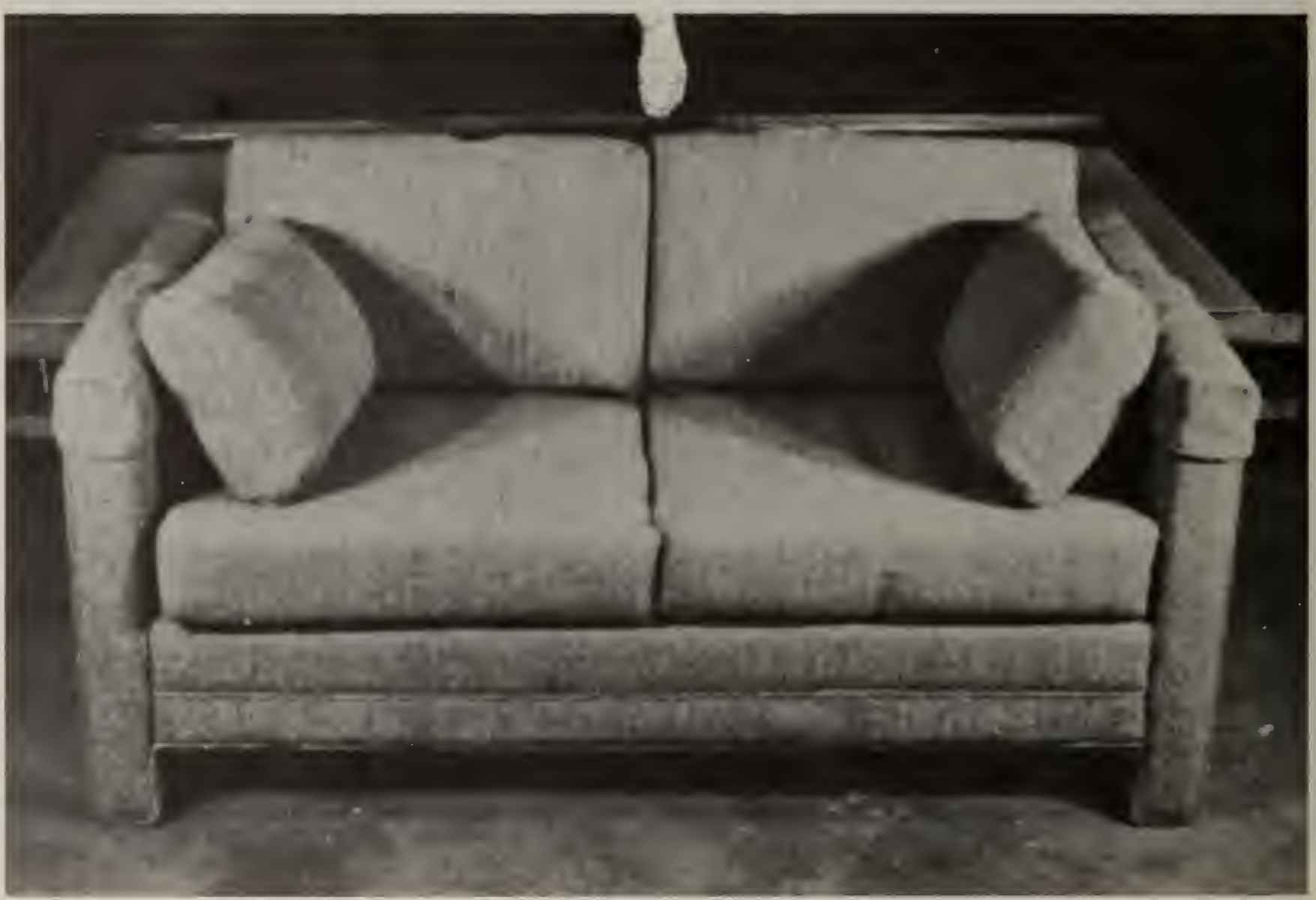

Figure 7. Chair F3I 


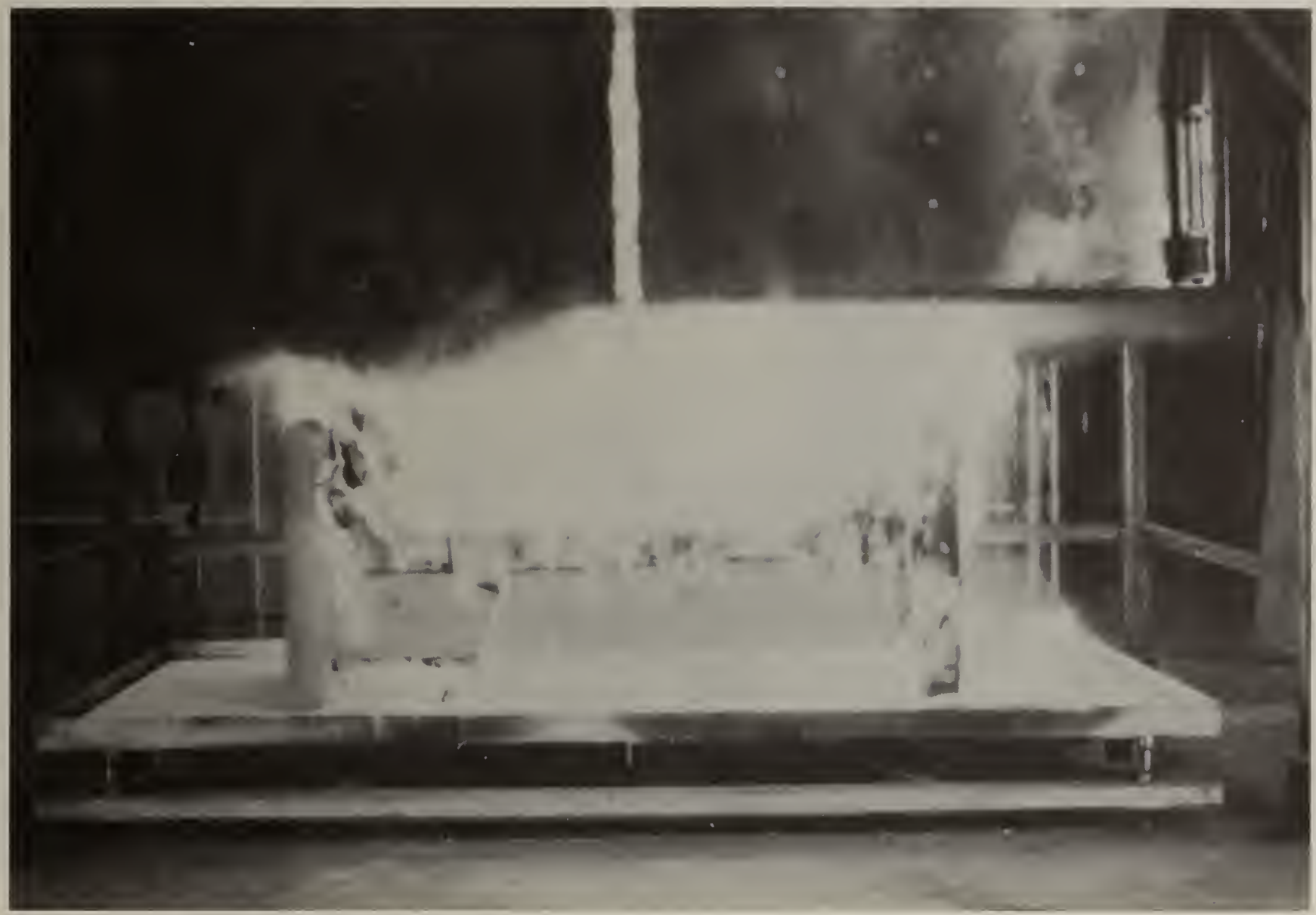

Figure 8. Chair F3I near peak burning time 


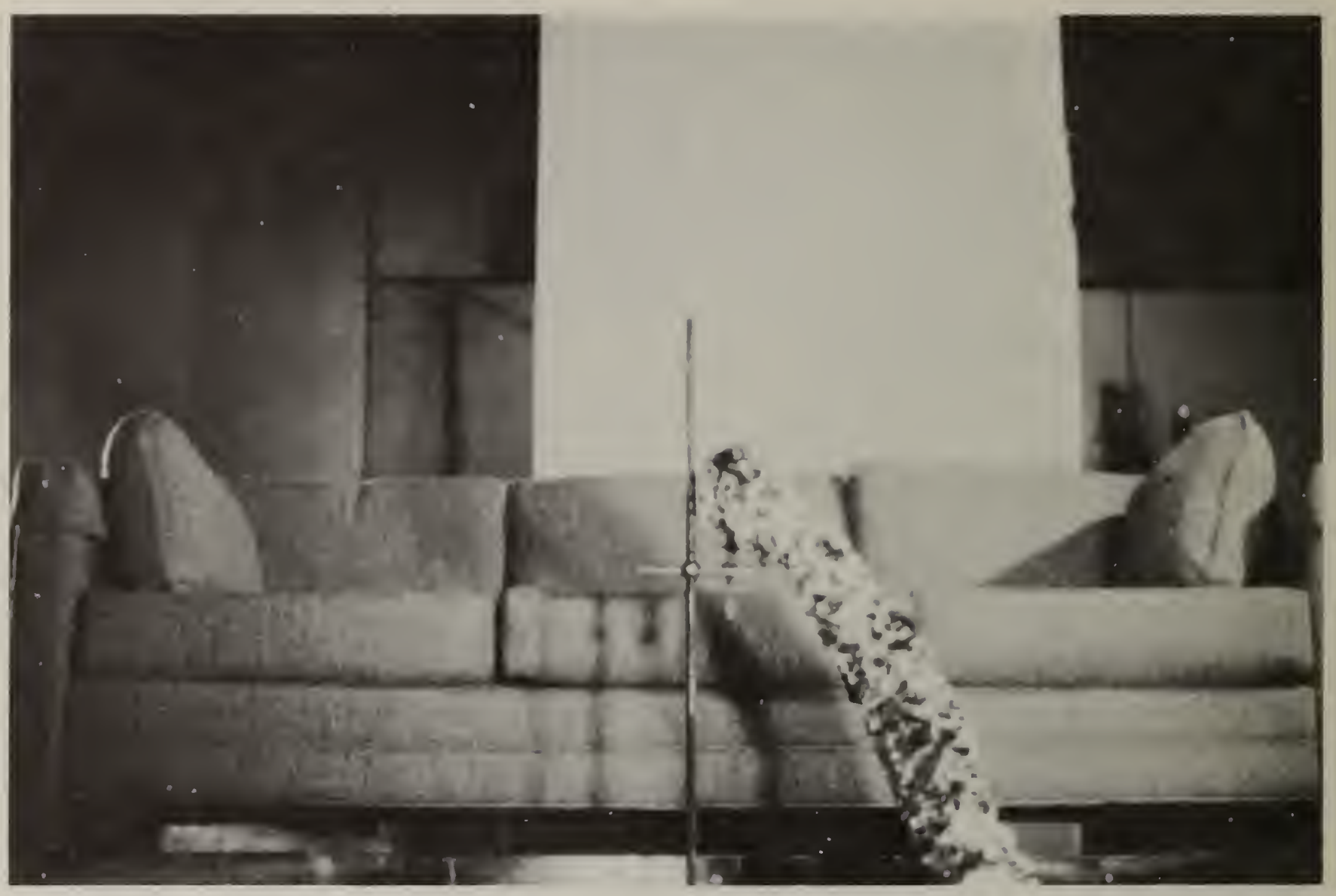

Figure 9. Chair F32 


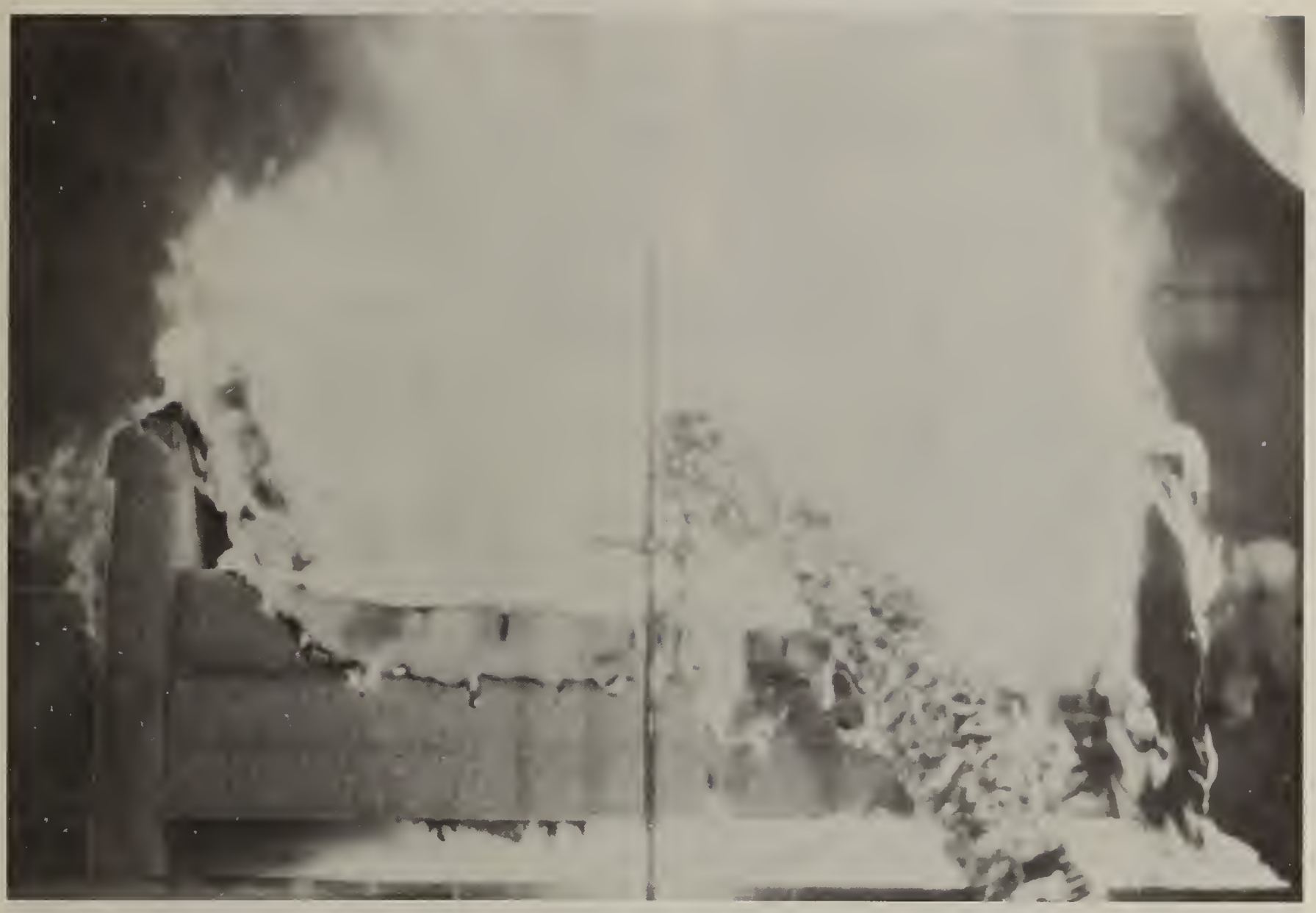

Figure 10. Chair F32 near peak burning time 


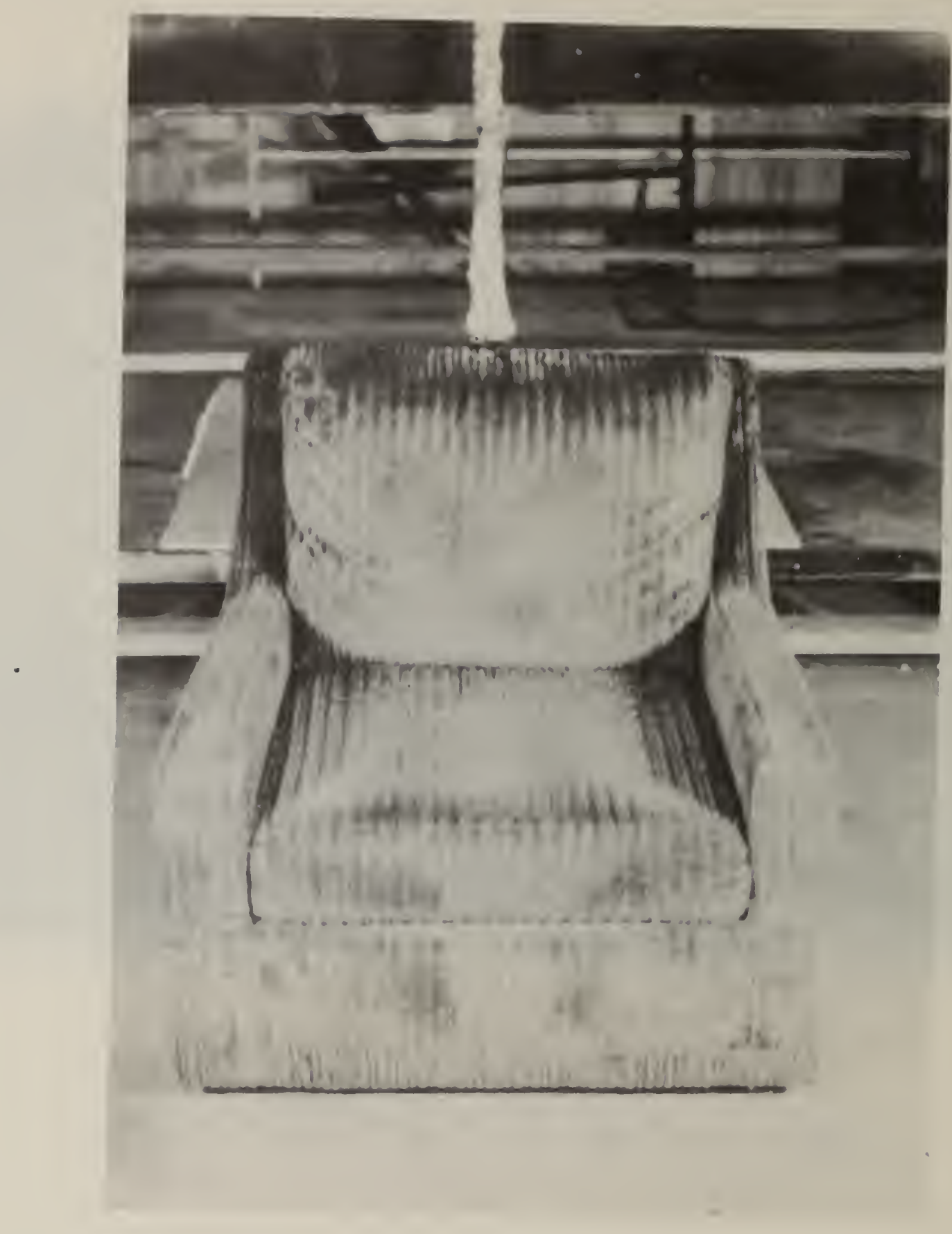

Figure 11. Chair F28 


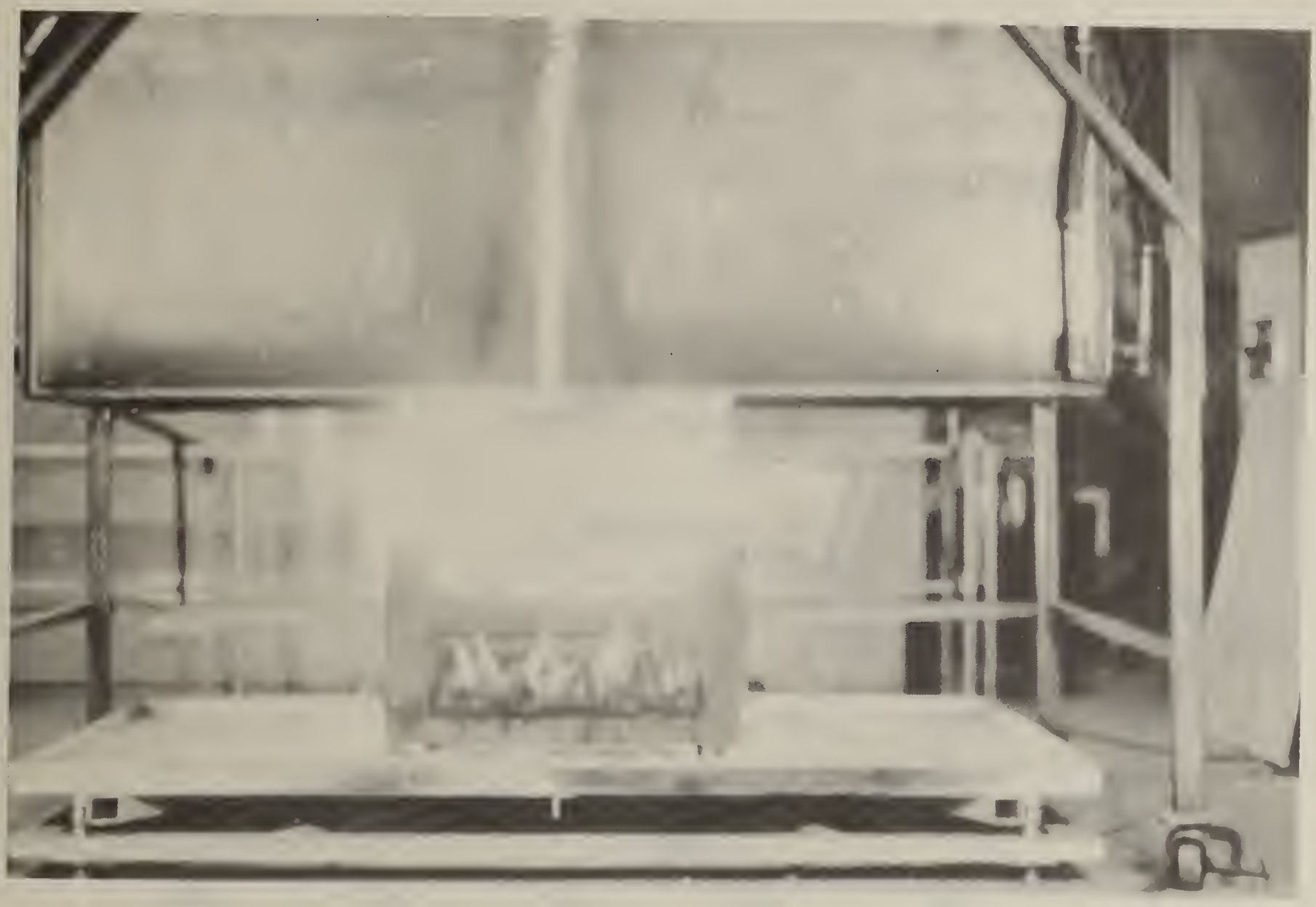

Figure 12. Chair F28 near peak burning time 


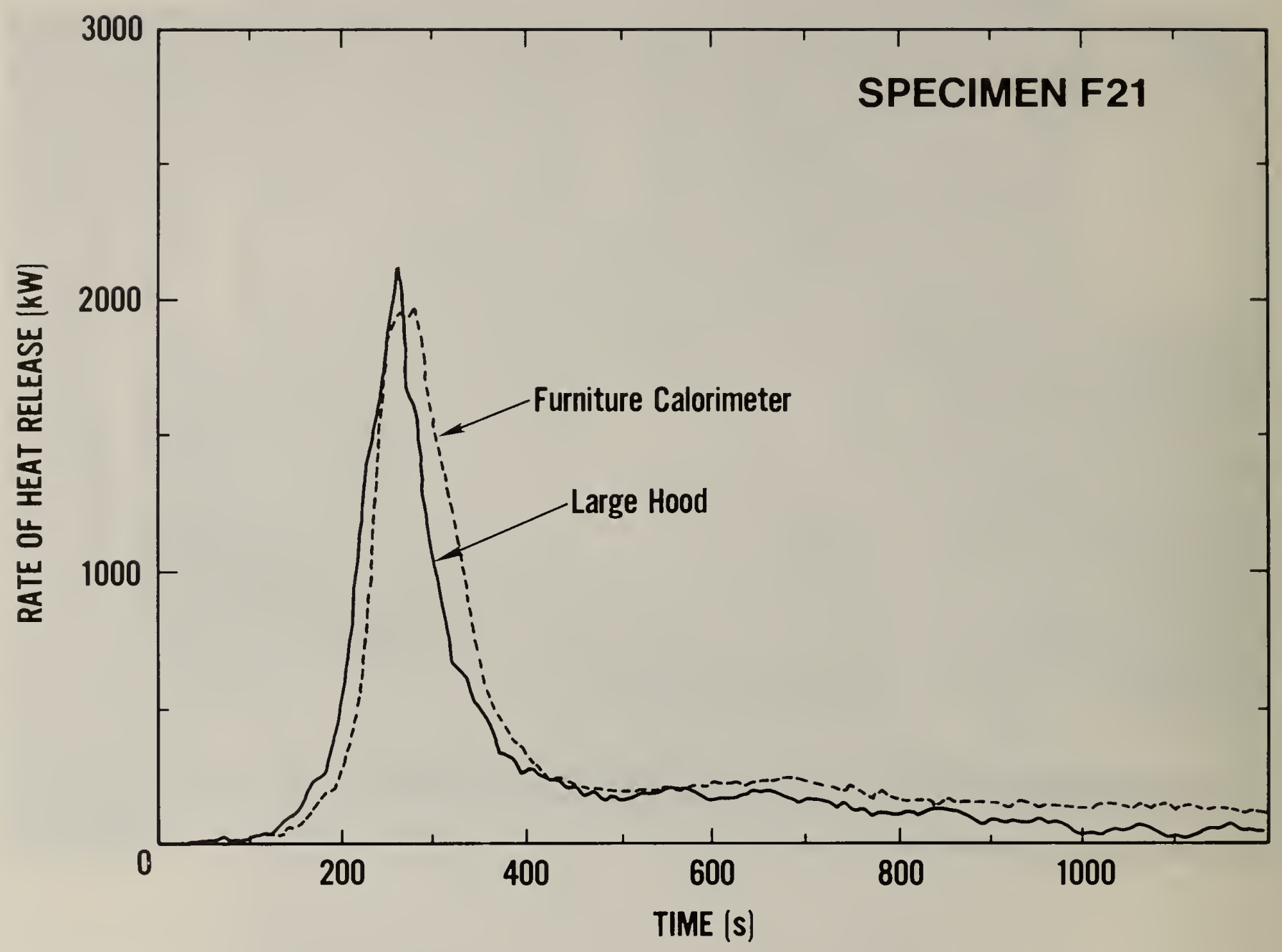

Figure 13. Rate of heat release for specimen F21 


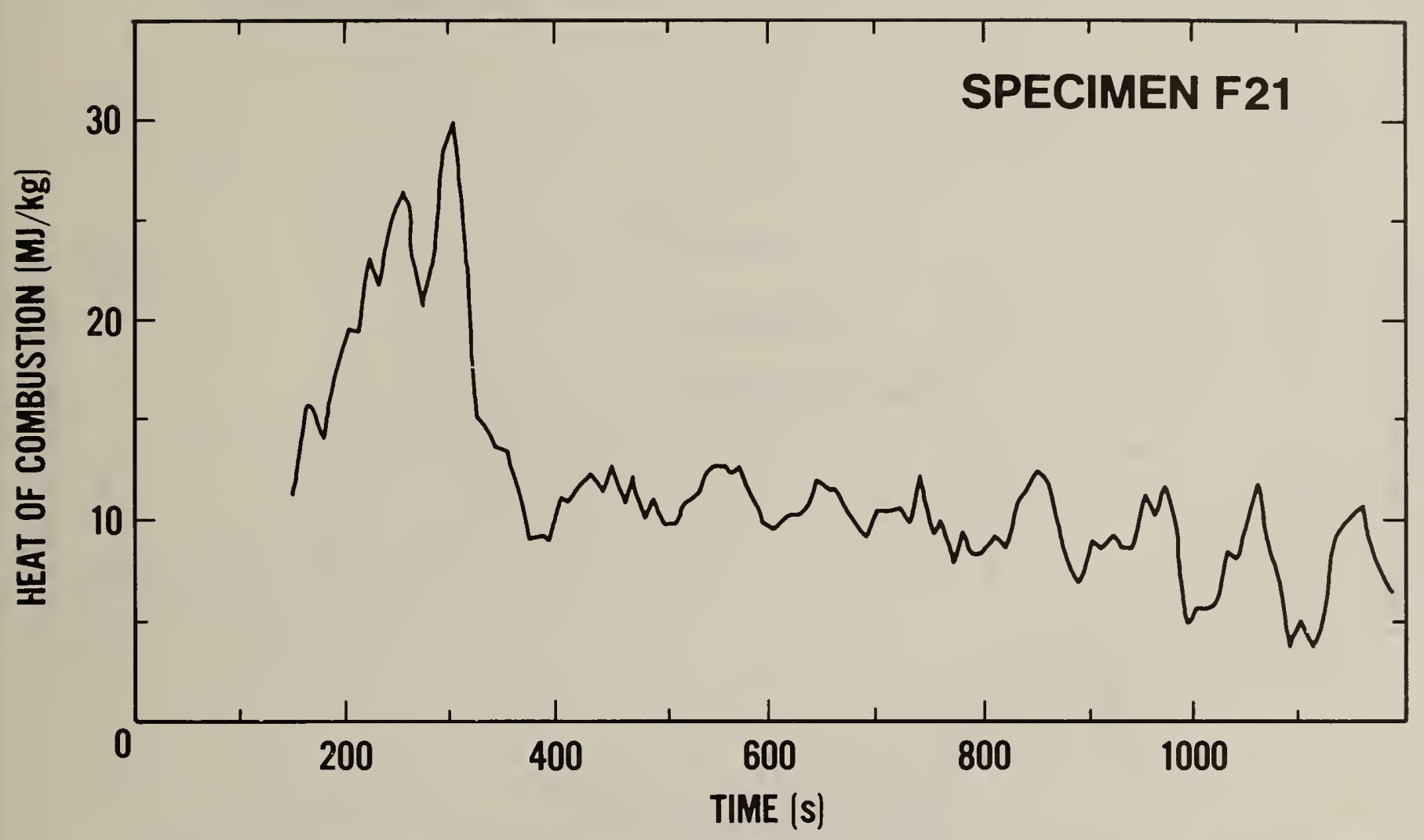

Figure 14. Effective heat of combustion measured for specimen F2l 


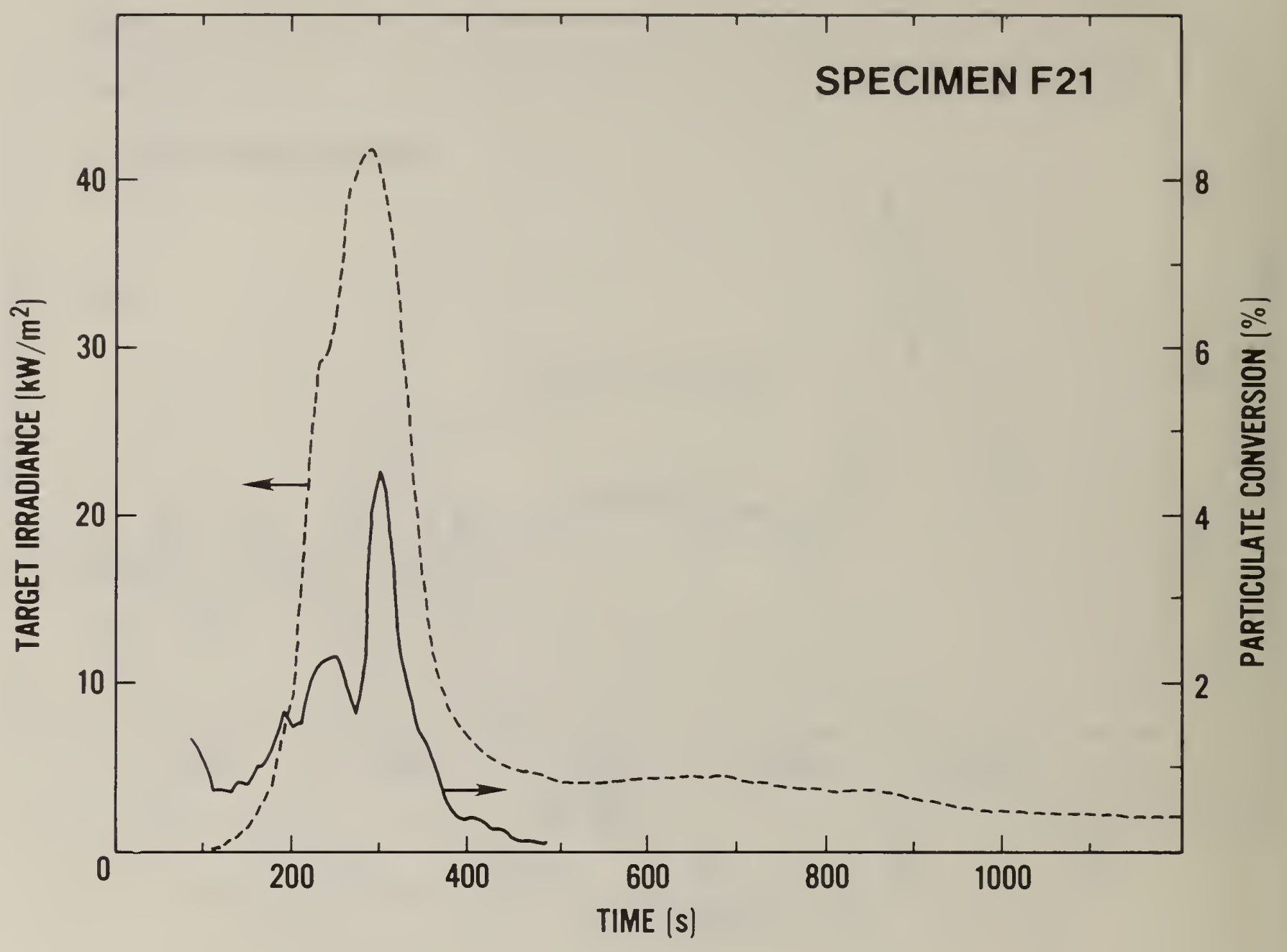

Figure 15. Target irradiance and particulate conversion fraction for specimen F2I 


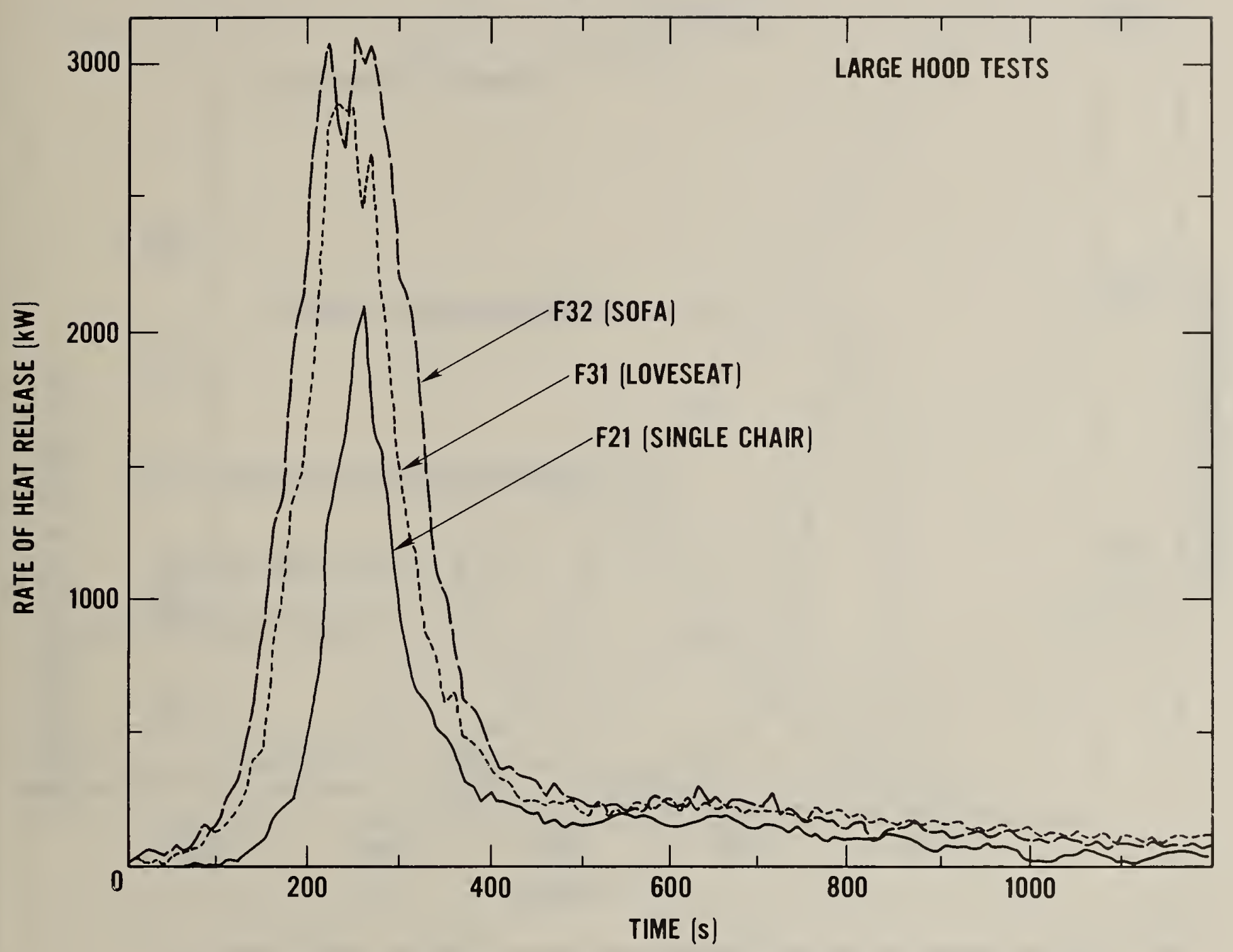

Figure 16. Effect of specimen mass on rate of heat release 


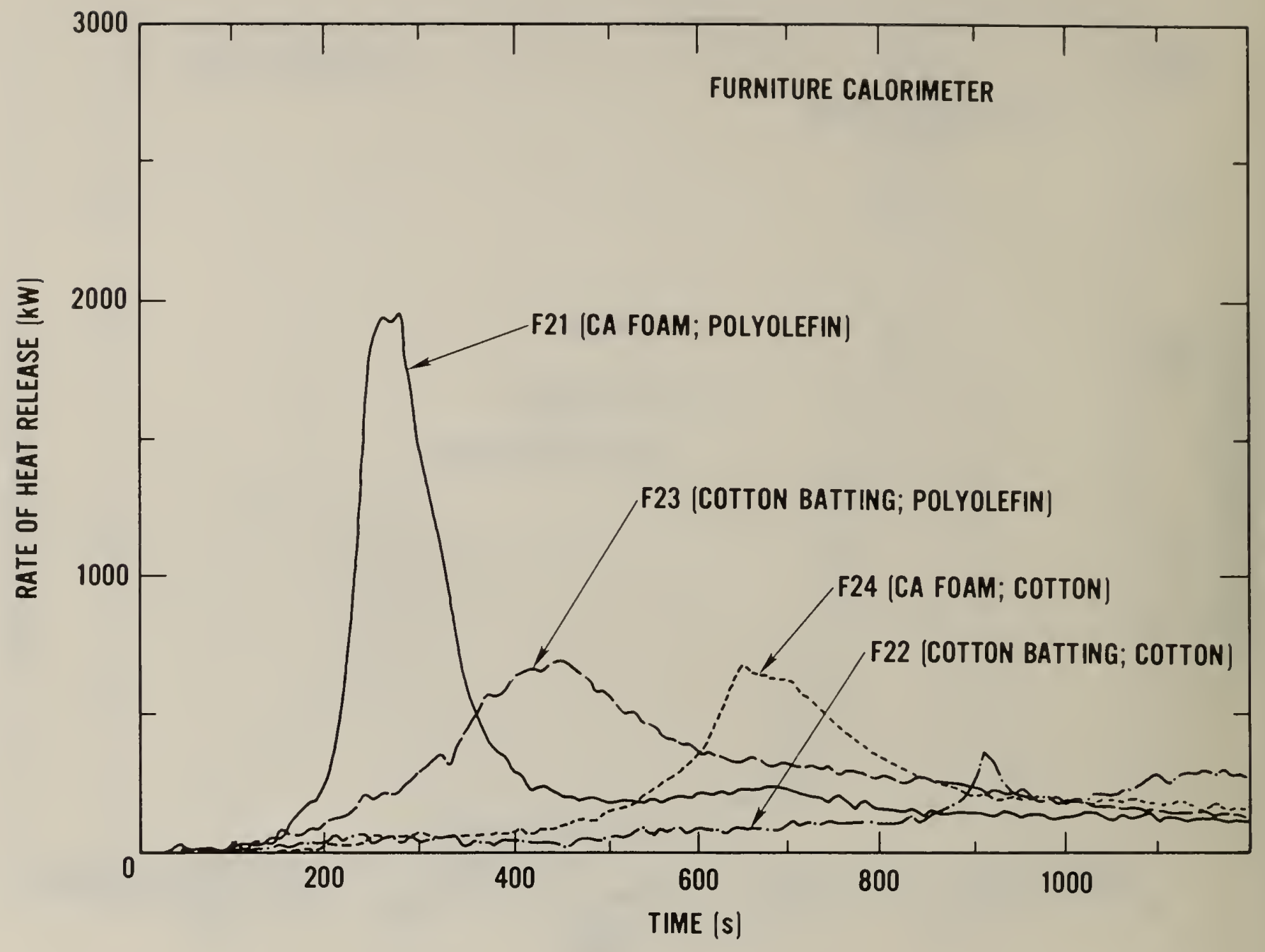

Figure 17. Effect of specimen padding and fabric on rate of heat release 


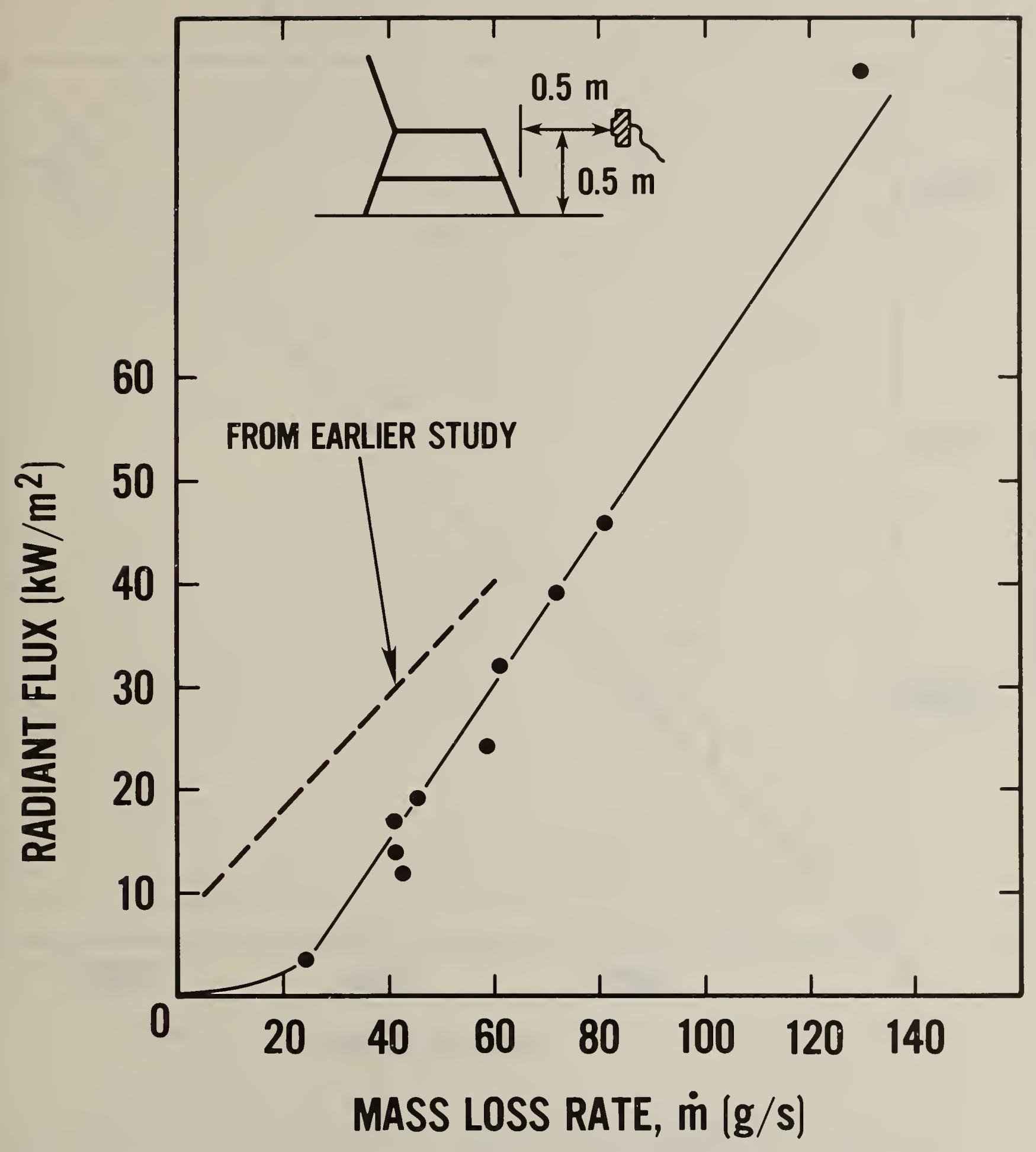

Figure 18. Relationship between mass loss rate and target irradiance flux 


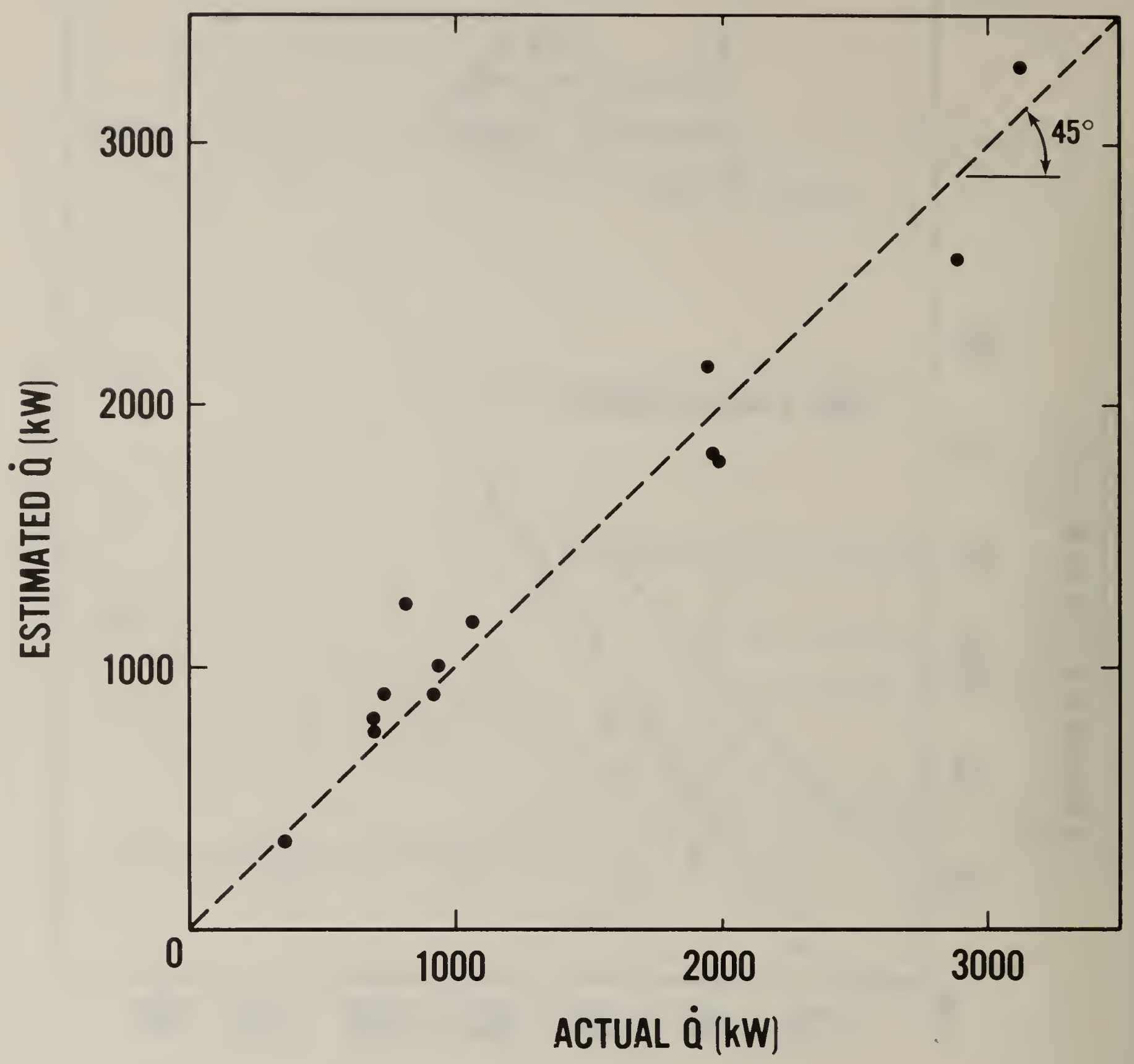

Figure 19. Relationships between actual and estimated peak values of rate of heat release 
Previous knowledge, together with analysis of raw data indicated that in an analysis system of the kind used here, slow instrument response is a problem that must be addressed. Some of the instruments used in the calorimeter (e.g., stack thermocouples) respond quickly enough that no response correction needs to be made. However, gas measuring instruments show a slower response for two reasons: (1) a certain lag time is involved in pumping the gases from the stack, through traps and filters, and into the gas analyzers. In the present case, this amounts to approximately $30 \mathrm{~s}$. The appropriate correction is simply made by performing a $30 \mathrm{~s}$ translation of the time coordinate; (2) instrument response itself is not instantaneous. This can be compensated for if the response characteristics are known.

The $\mathrm{O}_{2}$ and $\mathrm{CO}_{2}$ analyzers were tested by using the calibration burner to provide a square-wave heat release signal. For the turn-on portion, special precautions are required if a pressure spike is to be avoided. It is difficult to arrange this for flows of the magnitude needed here; consequently, only the data from the turn-off portion of the response were used. The decay transient is not subject to this error. Gas flow rates corresponding to 250 , 500,750 , and $1000 \mathrm{~kW}$ fires were used. Analysis indicated that the normalized response was identical for each of these cases and could be represented as

$$
U(t)=1-e^{-\beta t}
$$

where $U(t)$ is the response at time $t$ to a unit driving function, with the steady state value being $U(t \rightarrow \infty) \equiv 1.0$. The above is expressed, for simplicity, as the turn-on response. Values of $\beta$ were constant for each instruments and were

$$
\begin{aligned}
& B=0.08 \mathrm{~s}^{-1}\left(\mathrm{O}_{2} \text { analyzer }\right) \\
& \beta=0.25 \mathrm{~s}^{-1}\left(\mathrm{CO}_{2} \text { analyzer }\right)
\end{aligned}
$$

The relation between $\beta$ and the 10 percent to 90 percent $r i s e$ time $t_{r}$ is expressed as

$$
t_{r}=2.197 / \beta
$$


and is equal to $27 \mathrm{~s}$ for the oxygen analyzer and $8.8 \mathrm{~s}$ for the $\mathrm{CO}_{2}$ analyzer. The "time constant" can also be obtained as $t_{c}=1 / \beta$. The above values are largely, but not completely, a function of the analyzer alone. A slightly different response might be obtained if the square-wave input were presented directly at the inlet port of the instrument. The difference would be accountable by species diffusion in the sampling lines. Measurements of $\beta$ for the analyzers alone were not made since these data would not he used.

For a meaningful response correction to be made, $\beta \Delta t$ must be significantly smaller than 1.0, where $\Delta t$ is the data sampling interval. In the present apparatus $\Delta t=10 \mathrm{~s}$ was used for the earlier tests, with $\Delta t=5 \mathrm{~s}$ for later tests. Since $\Delta t$ could not be reduced below $5 \mathrm{~s}$, corrections for $\mathrm{CO}_{2}$ analyzer response would not be meaningful. Thus, no $\mathrm{CO}_{2}$ response corrections were made beyond the lag time adjustment.

A number of corrections schemes for $\mathrm{O}_{2}$ were examined. The simplest scheme is to let

$$
S(t)=R(t)+\frac{1}{\beta} \frac{\Delta R}{\Delta t}
$$

The adjusted response, $S$, is expressed as the measured response, $R$, plus a term proportional to the time-derivative of $R$. The derivative has to be evaluated numerically as a forward, central, or backward difference, but in any case, uses only two data points. This method was tried and it was found that while the response rise and fall times were sharpened up, an excessive amount of numerical hash was introduced. This hash is not unexpected since the correction at each step is based on only two data points, and has been noted by others [17].

A more powerful technique is based on the superposition integral. For a linear system the response can be expressed as

$$
R(t)=\int_{0}^{t} \dot{S}(\tau) U(t-\tau) d \tau
$$

where $\dot{\mathrm{S}}$ denotes $\mathrm{dS} / \mathrm{d} \tau$. Evans and Breden [18] have indicated how to solve this integral in finite-difference form to obtain $S(t)$. The expression for $S(t)$ then contains a summation of $R(t)$ terms starting at $t+\Delta t$ and going back to $t=0$. The terms near the origin, however, do not become small for $t$ $>0$, thus numerical errors near the origin propagate throughout. Also, the summation gets very long for large $t$ values. 
An equivalent superposition integral can be written as

$$
R(t)=\int_{0}^{t} S(\tau) \dot{U}(t-\tau) d \tau
$$

$\dot{U}$ can be obtained this way as an "impulse response" to a unit impulse at $t=$ 0 . More conveniently, since $\dot{U}=d U / d(t-\tau)$, this gives $\dot{U}=\beta e^{-\beta(t-\tau)}$.

For convenience we will take $\Delta t$ to be constant and define

$$
s_{n} \equiv s\left(t_{n}\right)=s(n \Delta t)
$$

A suitable finite-difference expression for $S_{n}$ then becomes*

$$
S_{n}=\frac{1}{1-e^{-\beta \Delta t}} R_{n+1}-e^{-\beta \Delta t} S_{n-1}-e^{-2 \beta \Delta t} S_{n-2}-\ldots \cdot e^{-n \beta \Delta t} S_{0}
$$

In this expression, in principle, all terms from $\mathrm{S}_{\mathrm{n}-1}$ to $\mathrm{S}_{\mathrm{o}}$ would have to be included. In practice, one can see that the experimental factors rapidly

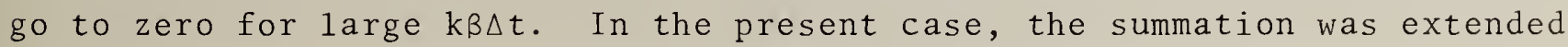
only to $\mathrm{k} B \mathrm{t}=7$. The expression thus has the desired properties--a sizeable number of points, much greater than 2 , is used to evaluate the adjustment, but the process is damped and values near the origin are immaterial at times much past the origin.

It can further be noted that a correction of this kind is worthwhile only when the sampling rate is sufficiently fast compared to instrument response time, so that $\beta \Delta t<1$. Thus, for the $\mathrm{CO}_{2}$ analyzer, in the present case, no correction was used.

When both a physical lag time correction and a square-wave correction have both to be made, as in the case of $\mathrm{O}_{2}$ response, it can be seen that the proper numerical lag time to be used is (physical lag) minus ( $\Delta t$ ).

* This form was suggested by P. Goodeve, University of California, Berkeley. 
Some exploratory experiments were conducted at variable fan speeds and heating rate values to determine the effect of fire size on system flow rate. It was noted that wile the standard volume flow and mass flow rates drop with increasing $\dot{Q}$, the actual volume flow rate--which in fan systems typically remains constant--rises somewhat with increasing $\dot{Q}$. Analysis of these data showed that, to a good approximation, the actual volume flow rate could be expressed as

$$
\dot{V}=C_{2} \sqrt{\Delta P_{E}}+1.091 \times 10^{-3}(\dot{Q}-55)
$$

applicable over the range of $100 \mathrm{kH} \leq \dot{Q} \leq 500 \mathrm{kll}$. Here $\mathrm{C}_{2}$ is a constant characterizing the fan and $\Delta \mathrm{P}_{f}$ is the pressure drop across the fan. $\dot{V}$ is seen to be expressable as a sum of two terms.

The actual volume flow through a fan is essentially constant when the intake gas density changes, provided the shaft speed remains the same and provided the system flow resistance remains constant. In the present case introducing heat into the system decreases the flow resistance and thus the actual volume flow rate rises with $\dot{Q}$. The mass flow rate falls, but does not fall as much as it would if the actual volume flow were constant. Measurements show that an alternate expression is possible,

$$
\begin{aligned}
& \dot{V} \simeq 1.4+0.0015 \mathrm{~T}\left(\mathrm{~m}^{3} / \mathrm{s}\right) \text { heating } \\
& \dot{\mathrm{V}} \simeq 1.4+0.0012 \mathrm{~T}\left(\mathrm{~m}^{3} / \mathrm{s}\right) \text { cooling }
\end{aligned}
$$

where $T$ is the stack temperature (K) measured at the location of the velocity probe. The above pair of expressions is valid for $0<\dot{Q} \leq 2000 \mathrm{k}$. Mass flows can then be calculated as:

$$
\begin{aligned}
& \dot{\mathrm{m}}_{\mathrm{a}} \simeq \frac{490}{\mathrm{~T}}+0.53(\mathrm{~kg} / \mathrm{s}) \text { heating } \\
& \dot{\mathrm{m}}_{\mathrm{a}} \simeq \frac{490}{\mathrm{~T}}+0.42(\mathrm{~kg} / \mathrm{s}) \text { cooling }
\end{aligned}
$$

The expressions for flow rates given above were derived only to illustrate system performance; all flow rates used elsewhere in this report were based on actual duct velocity and temperature measurements. 
In the furniture calorimeter the smoke measuring location is quite a distance downstream of the combustion zone (approximately $13 \mathrm{~m}$ ). The soot that is deposited on the duct walls is not available at the measuring station, and thus the measurement underestimates the actual smoke production. The stack duct flow is turbulent, so literature values for turbulent aerosol deposition in pipe flow can be examined. No studies directly applicable to fire smokes are available, but some data correlations are available for small solid particles flowing in ducts with wall surfaces of perfect adherence.

As customary in this area, we use a deposition velocity $K$

$$
K=\frac{\text { particles deposited }}{m^{2} s} \cdot \frac{m^{3}}{\text { particles }}
$$

The units of $\mathrm{K}$ are $\mathrm{m} / \mathrm{s}$ and represent the particle flux for a given freestream particulate concentration. This can be expressed non-dimensionally as $\mathrm{K} / \mathrm{u}$, where $\mathrm{u}=$ average duct flow velocity $(\mathrm{m} / \mathrm{s})$. By use of turbulence analogies we directly use results from turbulent heat transfer by letting

$$
\frac{\mathrm{K}}{\mathrm{u}} \sim \frac{\mathrm{Nu}}{\mathrm{ReSc}}
$$

Here $\mathrm{Nu}=$ Nusse1t number,

$$
\begin{aligned}
& \operatorname{Re}=\frac{\mathrm{ud}}{\nu}=\text { Reynolds number } \\
& \mathrm{Sc}=\frac{v}{\mathrm{D}}=\text { Schmidt number }
\end{aligned}
$$

With $\mathrm{d}=$ duct diameter $(\mathrm{m}), \nu=$ air kinematic viscosity $\left(\mathrm{m}^{2} / \mathrm{s}\right)$, and $\mathrm{D}=$ particle diffusivity $\left(\mathrm{m}^{2} / \mathrm{s}\right)$. An appropriate expression for $\mathrm{Nu}$ [27] is

$$
\mathrm{Nu}=0.0118 \mathrm{Re}^{7 / 8} \mathrm{Sc}^{1 / 3}
$$

In the present case we set

$$
\begin{aligned}
\mathrm{d} & =0.3 \mathrm{~m} \\
\mathrm{u} & =18 \mathrm{~m} / \mathrm{s} \\
\nu & =0.5 \times 10^{-4} \mathrm{~m}^{2} / \mathrm{s} \\
\operatorname{Re} & =1.0 \times 10^{5}
\end{aligned}
$$


For smoke from flaming fires we can take a typical particulate diameter as $d_{p}$ $=0.5 \times 10^{-6} \mathrm{~m}[28]$. This corresponds to [27]

$$
\begin{aligned}
\text { D) } & =6.3 \times 10^{-11} \\
S C & =2.3 \times 10^{5}
\end{aligned}
$$

Thus this gives

$$
\frac{K}{u}=7 \times 10^{-7}
$$

A better estimate can be made by using relationships based on particle measurements which take into account inertial effects and boundary layer penetration by particles. A recent review by Liu and Ilori [29] provides a data correlation in graphical form. Their results can be approximated as

$$
\begin{aligned}
& V_{+} \simeq 0.2 \text { for } \tau_{+} \geq 50 \\
& V_{+} \simeq 0.045 \rho_{p}^{-0.56} \tau_{+} 1.6 \text { for } \tau_{+} \leq 5
\end{aligned}
$$

The non-dimensional quantities $V_{+}$and ${ }^{t} t$ are defined as

$$
\begin{aligned}
& V_{+}=\frac{K}{u} \frac{1}{\sqrt{f / 2}} \\
& \tau_{+}=\frac{1}{9} \sqrt{\frac{f}{2}} \frac{\rho_{p}}{\rho_{f}} \frac{u d_{p}}{v}
\end{aligned}
$$

The friction factor $\mathrm{f} / 2=0.0395 \mathrm{Re}^{-1 / 4} ; \rho_{\mathrm{p}}$ and $\rho_{\mathrm{f}}$ are particle and fluid densities $\left(\mathrm{kg} / \mathrm{m}^{3}\right)$, respectively. In our case take

$$
\begin{aligned}
& \rho_{p}=2000 \mathrm{~kg} / \mathrm{m}^{3} \\
& \rho_{f}=0.6 \mathrm{~kg} / \mathrm{m}^{3}
\end{aligned}
$$

This gives

$$
\frac{K}{u}=1.8 \times 10^{-4}
$$

The quantity that is desired is the fraction of particulates lost over the running length of the duct, $Y=13 \mathrm{~m}$ in this case. This is the ratio $\mathrm{n}(\mathrm{y}) / \mathrm{n}_{\mathrm{o}}$, where $\mathrm{n}(\mathrm{Y})$ is the particle concentration at the smoke meter and $\mathrm{n}_{\mathrm{o}}$ is the initial concentration. This value can be gotten by performing a mass balance on particles, 


$$
\frac{\pi d^{2}}{4} u(d n)=K \pi d n_{0}(d y)
$$

Integrating from $y=0$ to $y=Y$ gives

$$
\frac{\mathrm{n}(\mathrm{y})}{\mathrm{n}_{\mathrm{O}}}=\exp \left(-\frac{4 \mathrm{Y}}{\mathrm{d}} \frac{\mathrm{K}}{\mathrm{u}}\right)
$$

Using $\mathrm{K} / \mathrm{u}=1.8 \times 10^{-4}$ this gives $\mathrm{n}(\mathrm{Y}) / \mathrm{n}_{\mathrm{o}}=0.97$. In other words, only 3 percent of the particulates are removed due to wall losses. This value for duct losses should be augmented by elbow and orifice losses, for which no convenient estimates are available. This would still be a very small loss; further experimental work would be needed to make a better estimate.

The appropriate comparison for bench-scale smoke data would be with the NBS smoke density chamber [30]. Here measurement errors can arise due to oxygen depletion, incomplete mixing, and coagulation due to smoke aging, in addition to chamber wall losses. The latter may also be augmented by thermophoretic forces. Further, in the static smoke chamber, due to thermal stratification the deposition is not uniform but is preferential towards the ceiling.

A rough indication of combined losses can be obtained by measuring the decay rate of the extinction coefficient. Assume that the chamber volume is well stirred but that deposition takes place only on the ceiling. Define an effective boundary layer thickness $\delta$, such that

$$
K=\frac{D}{\delta}
$$

Then a balance on the particulates gives

$$
\mathrm{V}(\mathrm{dn})=\frac{\mathrm{ADn}}{\delta}(\mathrm{d} t)
$$

Integrating for a total time $t$ gives

$$
\frac{\mathrm{n}(\mathrm{t})}{\mathrm{n}_{\mathrm{o}}}=\exp \left(-\frac{\mathrm{AD}}{\mathrm{V} \delta} \mathrm{t}\right)
$$

Here $(V \delta / A D)$ is the time constant, $A$ is the ceiling area $0.56 \mathrm{~m}^{2}$ in this case), and $V$ is the chamber volume $\left(0.51 \mathrm{~m}^{3}\right)$. 
Measurements suggest that the decay time constant is about $500 \mathrm{~s}$. This gives

$$
\delta=\frac{(500)(0.56)\left(6.3 \times 10^{-11}\right)}{0.51}=3 \times 10^{-8}
$$

Since this $\delta$ is $\ll d_{p}$ it does not realistically represent a physical boundary layer thickness.

The time constant for the decay, however, may be used as an estimate for the effect of wall losses and related errors on a smoke production measurement. The effect will be small if the time during which active burning measurements are taken is $<500 \mathrm{~s}$. This burning period may typically be $200 \mathrm{~s}$. Thus, wall losses within the smoke chamber are only a minor source of error in testing specimens.

The above analysis would be strictly applicable if the smoke chamber window were always free of sooting. Smoke particles, however, are deposited on the window as well as the walls. Particles which leave the gas phase by deposition thus still have an effect on beam transmission since they may be deposited on the window. This is hard to evaluate and has not been considered in detail beyond simply assuming that all the deposition takes place after combustion has ceased and adjusting the beam transmission accordingly. 
1. PUBLICATION OR REPORT NO. NBSIR $82-2604$
2. Performing Organ. Report No.

BIBLIOGRAPHIC DATA

SHEET (See instructions)

4. TITLE AND SUBTITLE

Upholstered Furniture Heat Release Rates Measured With a Furniture Calorimeter
December 1982

5. AUTHOR(S)

Vytenis Babrauskas, J. Randall Lawson, W. D. Walton, William H. Twilley

6. PERFORMING ORGANIZATION (If joint or other than NBS, see instructions)

7. Contract Grant No.

NATIONAL BUREAU OF STANDARDS

DEPARTMENT OF COMMERCE

8. Type of Report \& Period Covered

WASHINGTON, D.C. 20234

9. SPONSORING ORGANIZATION NAME AND COMPLETE ADDRESS (Street. City, State, ZIP)

10. SUPPLEMENTARY NOTES

[.] Document describes a computer program; SF-185, FIPS Software Summary, is attached.

11. ABSTRACT (A 200-word or less foctual summary of most significant information. If document includes a significant bibliography or literature survey, mention it here)

Accurate burning rate information on upholstered furniture is important for two purposes - to predict the room fire development history for a fire involving the furniture, and to relatively, but adequately, rank commercial products for a given application. Small-scale test results data not referenced to full-scale fires lack validity, while full-scale room fires are costly and lack generality. To enable simplified but realistic full-scale testing to be done, a new apparatus, termed a furniture calorimeter was developed. Rates of heat release are measured by using the oxygen consumption principle. Tests were conducted in the furniture calori-meter on thirteen different specimens of upholstered furniture, representing typical, but carefully controlled. construction. The results showed significant heat release differences between thermoplastic and cellulosic fabrics, between frame types and between padding materials. For polyurethane foam padding, however, performance was unrelated to results of Bunsen burner type tests on the foam. Thee data developed (1) can be used directly in the calculation of room fire growth; (2) will form some of the reference data for development of appropriate bench-scale test procedures; and (3) can be used in some cases to estimate burning rates of sjmilar but not identical furniture.

12. KEY WORDS (Six to twelve entries; alphabetical order: capitalize only proper names; and separate key words by semicolons)

Burning rate; chairs; fire tests; flammability tests; furniture; plastics; heat release rate; textiles, upholstered furniture.

13. AVAILABILITY

[X Unlimited

$\square$ For Official Distribution. Do Not Release to NTIS

$\square$ Order From Superintendent of Documents, U.S. Government Printing Officc, Washington, D.C. 20402.

14. NO. OF

PRINTED PAGES

Order From National Technical Information Service (NTIS), Springfield, VA. 2216I

73

15. Price 


